\title{
EVOLUÇÃO PETROLÓGICA E GEOQUÍMICA DO COMPLEXO BOM JARDIM, PERNAMBUCO
}

\author{
IGNEZ P. GUIMARÃES* \& ADEJARDO F. SILVA, F'*
}

\begin{abstract}
THE PETROLOGICAL AND GEOCHEMICAL EVOLUTION OF THE SHOSHONITIC BOM JARDIM COMPLEX, PERNAMBUCO STATE,NORTHEASTERN BRAZIL. The Bom Jardim complex of Brasiliano age (600 Ma) comprises amulti phase intrusion of syenitic and monzonitic composition, cut by late granites. Low angle foliation within the complex, indicated by alignment of euhedral minerals, runs parallei to the main thrust faults within the region. This suggested that the emplacement of the complex could by related to the thrust faulsts. The major and trace elements geochemistry has establ ished amantle source for both syenites an monzonites, while the granites have been interpreted as the result of crustal melting. Fractionation of mainly amphibole, biotite, alkali feldspar, plagioclase within the syenite and monzonite suite, appears to be the main differentiation process taking place. The enrichment in LILE/HFSE ratios and low Sr87/Sr86 + 0.70709, compared with crustal granitoids, recorded in the syenites and monzonites, are considered to be consistent with an origin by partial melting of a metasomatized mantle as it occurs above a subduction zone.
\end{abstract}

Keywords: Syenite, shoshonite, Brasiliano, metasomatized mantle.

RESUMO O Complexo Bom Jardim, de idade brasiliana (600 Ma), é constituído por intrusões múltiplas de composições sien íticas e monzoníticas, cortadas por granitos tardios. Foi iação de baixo ângulo, dada pelaorientação de minerais euedrais e subedrais, paralelas as falhas de empurrão regionais, parece indicar que o complexo representa intrusão relacionada àtectônica tangencial. A geoquímica dos elementos maiores e traços estabeleceu origem mantél ica para os sienitos e monzonitos, enquanto os granitos parecem representar magmas gerados por fusão crustal. Fracionamento principalmente de anfibólio, biotitae feldspato alçai ino, e plagioclásio, em menor escala, foram os principais processos envolvidos na evolução dasuítesienito-monzonito.Oenriquecimento em LILE, altas razões LILE/HFSE ebaixa razão inicial Sr87/Sr86+0,70709, em comparação agranitóides de origem crustal, nos sienitose monzonitos, são compatíveis com origem a partir da fusão parcial de manto metassomatizado, como ocorre em regiões acima de zonas de subducção.

Palavras-chaves: Sienito, shoshonito, Brasiliano, manto metassomatizado.

INTRODUÇÃo As rochas do Complexo Bom Jardim foram intrudidas em gnaisses e migmatitos da faixa Pajeú Paraíba, próximo ao seu contato com o Maciço Pernambuco - Alagoas (PE/AL) (Brito Neves 1975), durante o Brasiliano (aproximadamente $600 \mathrm{Ma}$ ) (Guimarães 1989). Os dados de campo têm revelado que o maciço PE/AL foi empurrado sobre a faixa Pajeú - Paraíba (Brito Neves et al. 1982). Esta faixa, onde ocorrem os empurrões, coincide com o alinhamento de anomalias Bouger negativas descritas por Brito Neves et al. (1982), parecendo refletir espessamento crustal na região. O maciço PE/AL constitui unidade cratogênica (Mello et al. 1977), com forma triangular, constituído de terrenos gnáissicomigmatíticos, batólitos graníticos e granodioríticos e terrenos supracrustais representados pelas coberturas dobradas. $\mathrm{O}$ metamorfismo é, principalmente, da fácies anfibolito, embora ocorra localmente metamorfismo na fácies anfibolito em condições de P-T. O maciço é cortado e circundado por granitóides de idade brasiliana.

Os metassedimentos expostos na borda norte do maciço, no contato com a faixa Pajeú - Paraíba, encontram-se bastante tectonizados, difícultando a determinação do limite preciso entre os metassedimentos do maciço e os da faixa.

A faixa Pajeú - Paraíba, de idade proterozóica inferior a média (Jardim de Sá 1984), apresenta uma forma aproximadamente oval. Litologicamente, é constituída por migmatitos, biotita gnaisse, granada-biotita xistos, filitos, clorita xistos, metagrauvacas, quartzitos e mármores. O metamorfismo está dentro das condições P-T da fácies anfibolito. A faixa Pajeú - Paraíba é caracterizada por intenso magmatismo, refletindo diferentes estágios: stocks tardios, stocks de gabro e diorito, diques e lentes de ortoanfibolito e ortopiroxenitos marcando a fase inicial, granitos sinorogênicos e stocks tardios de sienitos e quartzo sienitos (540 Ma) (Brito Neves 1975).

DESCRIÇÃO GEOLÓGICA O Complexo Bom Jardim constitui intrusão alongada cobrindo área de $200 \mathrm{~km}^{2}$, cortando migmatitos e gnaisses da faixa Pajeú-Paraíba (ou leste de Pernambuco), de possível idade proterozóica inferior (Jardim de Sá 1984). O eixo principal do complexo é geralmente paralelo à foliação regional, acompanhando grosseiramente a direção de contato entre a faixa Pajeú-Paraíba e o Maciço Pernambuco Alagoas. A foliação das rochas do complexo, determinadas pelo alinhamento de feldspatos subedrais e euedrais e os máfícos biotita e anfibólios, mostra uma direção geral NE-S W mergulhando suavemente $\left(5^{\circ}-40^{\circ}\right)$ para SE. Observações de campo e microscopia não mostraram evidências de deformação no estado sólido segundo esta direção de foliação. A forma geral euédrica dos feldspatos e a presença de biotita não-alterada refletem deformação em temperaturas acima de $450^{\circ} \mathrm{C}$ (Berthe et al. 1979). Plutões intrudidos sincronicamente com a deformação regional mostram aspecto de deformação envolvendo fundido mais cristais (Hutton 1987). Muitas das características descritas por Hutton (1987) têm sido observadas no Complexo Bom Jardim, evidenciando intrusão sin a tardi-cinemática.

A foliação de baixo ângulo do complexo de direção paralela aos principais traços das falhas de empurrão regional, associada às evidências de deformação no estado plástico, sugerem que a intrusão do Complexo Bom Jardim está relacionada a tectônica tangencial. Cisalhamentos pós-intrusão são obser-

\footnotetext{
* Departamento de Geologia, Centro de Tecnologia, Universidade Federal de Pernambuco, Avenida Professor Moraes Rego, s/n ${ }^{\circ}$, CEP 05067-901, Cidade Universitária, Recife, PE, Brasil
} 


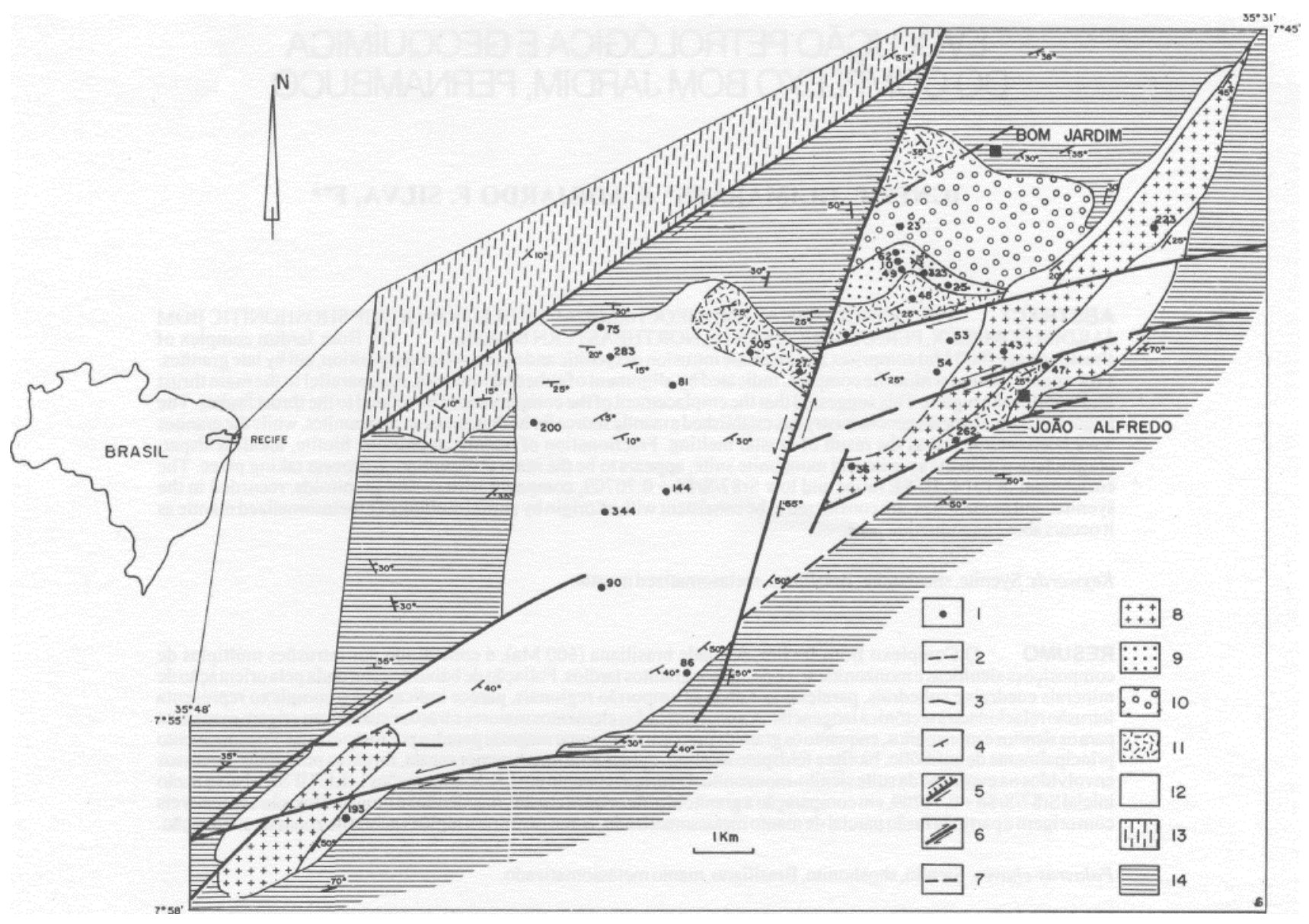

Figura 1 - Mapa geológico simplificado do Complexo Bom Jardim. 1. localização das amostras listadas na tabela 1; 2. contato inferido; 3. contato observado; 4. foliação; 5. falha com rejeito direciona/ e forte componente vertical; 6. falha de rejeito directorial;7. fraturas; 8. granitos; 9. piroxênio, biotita sieniíos leucocráticos; 10. piroxènio, biotita, anfibólio sienito mesocrático de granulação média; 11. sienitos marrons extremamente grossos; 12. piroxênio, biotita, anfibólio mela-sienitos e mela-monzonitos; 13. biotita xistos e biotita gnaisses da Faixa Pajeú-Paraíba; 14. gnaisses e migmatitos do Maciço PE-AL Figure 1 - Simpliffied geologic map of the Bom Jardim complex. 1. location of samples from table 1; 2. inferred contact; 3. observed contact; 4. foliation; 5. strike slip fault with downthrow; 6. strike slip fault; 7. fracture; 8. granites; 9. pyroxene, biotiteleucocratic syenites; 10. pyroxene, biotite,amphibole,mesocratic, medium grained syenites; 11. very coarse grained brown syenites; 12. pyroxene, biotite schist and biotite gneiss from Pajeú-Paraíba belt; 14. gneiss and migmatites from PE-AL massif

vados localmente, algumas vezes obliterando a tectônica tangencial e refletindo reativação do lineamento Pernambuco.

Falha com rejeito direcional sinistrai, forte componente vertical e direção NNE-SS W foi mapeada cortando o complexo na sua porção central (Fig. 1). Observações de campo, principalmente a falta de continuidade das fácies mais diferenciadas do complexo, que afloram na porção leste, sugerem que a porção oeste do complexo foi alçada e erodida, estando agora expostas rochas mais profundas que na porção leste.

Cinco fácies maiores foram identificadas e mapeadas no Complexo Bom Jardim (Fig. 1). Por causa da composição modal das rochas, texturas e os termos gerais da classificação doIUGS(Streckeisen 1976, Lê Bas\& Streckeisen 1991), foi adotada a seguinte denominação: piroxênio-biotita-anfibólio melasienitos e mela-monzonitos, porfiríticos (SMG); piroxênio-biotita-anfibólio sienitos, localmente porfiríticos, mesocráticos de granulação média (SM); piroxênio-biotita sienitos leucocráticos (LS); sienitos marrons muito grossos (SEG), e granitos róseos eqüigranulares finos (GRF). O contato entre as diversas fácies do complexo e as rochas encaixantes é geralmente feito por falhas. As diferenças faciológicas observadas são interpretadas como reflexo de processos de fracionamento ma«;mático e serão discutidas adiante.

\section{DESCRIC̃̃ES PETROGRAFICAS Fácies SMG}

A fácies SMG constitui o maior volume de rochas aflorantes. Estas rochas são caracterizadas por textura hipidiomórfica porfirítica, com fenocristais de feldspato alcalino e, menos freqüentemente, plagioclásio. A composição modal dos membros desta fácies mostra variação na proporção relativa de plagioclásio e feldspato alcalino (Tab. 1). Os feldspatos alcalinos são predominantes microclínio, macro e micropertita. Substituição de plagioclásio por feldspato alcalino é comum. Fenocristais de feldspato com textura rapakivi, ou seja, cristais ovóides de pertita circundados por plagioclásio de composição oligoclásio, ocorrem localmente. Plagioclásio apresentando fraca zonação normal, às vezes oscilatória, mostra variação composicional de An 25 a An 18 e é geralmente subedral a anedral. Intercrescimentos mirmequíticos freqüentemente observados nos cristais de plagioclásio próximos aos fenocristais de feldspato alcalino. Plagioclásio ocorre também como inclusões com bordos corroídos nos fenocristais de feldspato alcalino. Os diferentes hábitos de ocorrência do plagioclásio nesta fácies parecem refletir longo intervalo de cristalização. Quartzo ocorre em porcentagens modais menores que $5 \%$ e forma grãos anedrais geralmente com extinção ondulante. 


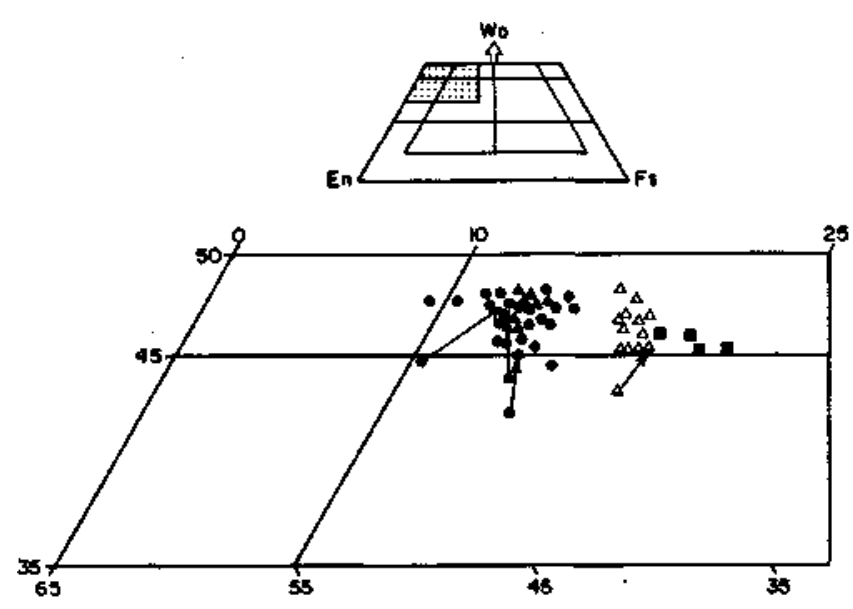

Figura 2 - Composições dos piroxènios do Complexo Bom Jardim projetadas no diagrama tetraedro Di-Hd-En-Fs. Círculos - SMG; triângulos cheios - SM; triângulos vazios $\boldsymbol{L S}$; quadrados-SEG. Setas indicam variação do núcleo para o bordo dentro do piroxênio

Figure 2 - Plot of the pyroxene composition from the Bom Jardim complex on Di-Hd-En-Fs tetrahedron. Closed circle - SMG; closed triangle - SM; open triangle - LS; closed square - SEG. Arrows indicate core to rim variations within single pyroxene

Tabela l - Análises modais do Complexo Bom Jardim Table 1 - Modal analysis of the Bom Jardim complex

\begin{tabular}{|c|c|c|c|c|c|c|c|c|c|}
\hline \multirow{2}{*}{$\frac{\text { FACES }}{\text { AMOSTRA }}$} & \multicolumn{4}{|c|}{ SNG } & \multicolumn{3}{|c|}{$\mathbf{S M}$} & \multicolumn{2}{|c|}{ LS } \\
\hline & 29 & 144 & 91 & 193 & 51 & 124 & 248 & 10 & 163 \\
\hline Quarto & 0,0 & 0,9 & 0.6 & 0.0 & 2,8 & 4,6 & 20 & 5.3 & 7,3 \\
\hline Feldsp. Alc & 36,0 & 21,6 & 17,1 & 37.0 & 590 & 46,9 & 63,0 & 73,4 & 68,8 \\
\hline Plagioctasio & 4,4 & 33,5 & 30,8 & 30,9 & 12,1 & 13,9 & 8,9 & 3,3 & 4,6 \\
\hline Botita & 25,0 & 14,9 & 32,8 & 30,9 & 14,2 & 17,5 & 13,2 & 9,7 & 10,1 \\
\hline Anfitólio & 27,0 & 27,4 & 1,6 & 12,0 & 1,6 & 9.7 & 4,2 & 0,0 & 1,0 \\
\hline Clnopiroxataio & 4,1 & 0,0 & 15,5 & 7,8 & 9,3 & 4,1 & 6,6 & 6,0 & 5,2 \\
\hline Zroto & 0,2 & 0,3 & 0,1 & 0,1 & 0,3 & 02 & $\checkmark$ & to & 0,1 \\
\hline Titanita & 2,2 & 0,3 & 0,0 & 0,6 & 0,1 & 1,2 & 0,3 & 0,2 & 0,1 \\
\hline Opaoos & t & 0,2 & 1,6 & 0,1 & 09 & 1,3 & 1,0 & 1,5 & 1,5 \\
\hline Alanita & 0,0 & 0,1 & 0,0 & $t$ & 0,0 & 0.0 & 0,0 & 0,0 & 0,0 \\
\hline Monazita & 0,0 & 0,0 & t & 0,0 & 0,0 & 0,0 & 0,0 & t & 0,0 \\
\hline
\end{tabular}

Feldsp. $A c_{c}=$ feldspato alcalino (microdinio e pertitas); or = traço

Anfibólios primários ocorrem como cristais euedrais a subedrais, associados a piroxênio ou em grãos isolados. São principalmente magnésio-hornblendaeedenita(Leake 1978). Hornblenda actinolítica, algumas vezes em intercrescimento simplectítico com quartzo, ocorre substituindo piroxênio no estado subsolidus. Piroxènios com composição de diopsídio (Wo En $\mathrm{Fs}_{13}$, em média) (Fig. 2) ocorrem em cristais subedrais fracamente zonados. Anfibólio, como coroas de reação em piroxênio são comuns e, em alguns cristais, apenas relíquias de piroxênio são observadas. Anfibólios primários, como bordas de reações em piroxênio, ocorrem principalmente em resposta à queda de temperatura e aumento de $\mathrm{PH}_{2} \mathrm{O}$ no líquido, normalmente seguindo prolongado intervalo de cristalização das fases anidras (Best \& Merci 1967).
A biotita não mostra distribuição modal uniforme nessa fácies (Tab. 1), e ocorre como placas subedrais, substituindo piroxênio e anfibólio. Inclusões de zircão e apatita são comuns. Os minerais acessórios mais comuns são apatita, titanita, zircão e magnetita. Allanita metamítica e nãometamítica, às vezes circundadas por epídoto, e cristais ovalados de monazita ocorrem esporadicamente.

Fácies SM É normal esta fácies apresentar textura eqüigranular xenomórfica com ocasional textura porfirítica. Análises modais (Tab. 1) mostram que feldspato alcalino (microclínio pertítico e microclínio) varia de $63 \%$ a $47 \%$ e plagioclásio (An 19 a An 11), de 9\% a 14\%. Borda albítica são freqüentemente desenvolvidos no plagioclásio, quando em contato com microclínio pertítico, indicando reequilíbrio no estado subsolidus (Smith 1974). Quartzo em porcentagens modais inferiores a $10 \%$ ocorre sempre como fase intersticial.

Piroxènios de composição diopsídio (Fig. 2) ocorrem como cristais subedrais fracamente zonados, ou como relíquias dentro de anfibólios. Substituições por anfibólios e biotita são freqüentes.

Os anfibólios são edenita e, com menor freqüência, hornblenda magnesiana. Biotita é, em geral, poiquilítica, com inclusões de apatita e zircão.

Titanita de origem primária e secundária ocorre nesta fácies corno o mineral acessório mais comum. Os grãos primários são geralmente euedrais a subedrais, de coloração laranjaavermelhada, contendo freqüentes inclusões de anfibólio e apatita, evidenciando a sua cristalização tardia na seqüência mineral. Titanita enriquecida em elementos terras raras leves (ETRL), circundando oxido de Fe e Ti, foi observada localmente. Esta associação, em particular, pode ser resultante da circulação tardia de fluidos, os quais carregariam elementos incompatíveis com a fase opaca (Fowler 1985).

Apatita e zircão ocorrem geralmente como inclusões euedrais em biotita e anfibólios, sugerindo cristalização nos estágios iniciais da seqüência magmática. Magnetita é o principal mineral opaco, enquanto óxidos de Fe-Ti são ocasionais. Monazita em grãos ovalados e cristais subedrais de minerais de tório, incluindo torita, foram observados localmente.

Fácies LS Esta fácies contém menos de $20 \%$ de teor modal de minerais máficos. A textura é hipidiomórfica fluidal, com tendência a porfirítica. Feldspato alcalino, principalmente microclínio pertítico, é a fase mineral mais abundante, chegando a constituir até $74 \%$ do total modal. Inclusões de hematita ao longo do plano (010), apatita, piroxênio e biotita são comuns.

Plagioclásio de composição albítica (An $1 \mathrm{O}$ - AnO) ocorre como pequenos cristais $(0,5 \mathrm{~mm}$ a $1,0 \mathrm{~mm})$ subedrais nãozonados, ocasionalmente associados a intercrescimentos mirmequíticos. Quartzo forma cristais anedrais intersticiais, com extinção ondulante, chegando a constituir até $7 \%$ do total modal.

As fases máfícas são principalmente biotita em placas poiquilíticas e piroxênio com composição de diopsídio (Fig. 2). Substituição de piroxênio por biotita é comum. Substituições subsólidas de piroxênio por anfibólio (hornblenda actinolítica) são observadas localmente ao longo dos planos de clivagem ou nos bordos de cristais. As composições dos piroxènios das diferentes fácies do Complexo Bom Jardim, projetadas no diagrama quadrangular Di-Hd-En-Fs (Fig. 2), mostram que os piroxènios da fácies LS são claramente mais enriquecidos na molécula Fs comparados aos piroxènios da fácies SEG e SM.

Os minerais acessórios são apatita, zircão, titanita, minerais não-metamíticos enriquecidos em terras raras leves e tório (titanita com y); esporadicamente, allanita e monazita. Às vezes, titanita ocorre manteando óxidos de Fe-Ti. Magnetita é a principal fase opaca. 
Fácies SEG Esta fácies é caracterizada por textura porfirítica com grandes fenocristais de feldspato alcalino (3 $\mathrm{cm}$ em média), os quais constituem de 60 a $90 \%$ do volume modal total. Existe clara tendência de decréscimo na concentração dos fenocristais do centro para a borda do plutão.

Os fenocristais são compostos por microclínio pertítico, mostrando distribuição zonal de intercrescimentos pertíticos grossos e finos. Inclusões de piroxênio, anfibólio e biotita formando zonas concêntricas nos fenocristais são observadas com freqüência. Inúmeras inclusões aciculares de minerais opacos são as prováveis repensáveis pela coloração cinzachumbo iridescente, observada em amostra de mão. As bordas dos fenocristais são geralmente irregulares e circundados por pequenos cristais anédricos de plagioclásio albítico e microclínio. Esta última feição, associada à presença de intercrescimentos pertíticos grossos intercalados com finos, são evidências da circulação de fluidos magmáticos tardios (Parsons 1978).

A matriz consiste de plagioclásio albítico (An5 a AnO), microclínio, piroxênio de composição diopsídio (Fig. 2), biotita e quartzo. Os acessórios são apatita, titanita, zircão e magnetita.

Granitos róseos GRF Os granitos são leucocráticos, de granulação média ( $2 \mathrm{~mm}$ em média), com textura eqüigranular xenomórfica. Feldspato alcalino, microclínio e microclínio pertítico ocorrem em grãos xenomórficos, com freqüentes inclusões de plagioclásio de composição oligoclásio (An 19 - An 17) ocorre como grãos subedrais e anedrais e contém freqüentes inclusões de titanita e allanita. Quartzo ocorre de forma xenomórfica intersticial, geralmente com extinção ondulante, em porcentagem modal bastante variável $(33 \%-17 \%)$. Biotita é o principal constituinte máfico, chegando até $9 \%$ do volume modal total. Inclusões de zircão são freqüentes. Allanita manteada por epídoto, titanita, zircão e apatita são os minerais acessórios.

GEOQUímICA Mais de 80 amostras do Complexo Bom Jardim foram analisadas para elementos maiores, mais $\mathrm{Ba}, \mathrm{Sr}, \mathrm{Cr}, \mathrm{Ni}, \mathrm{V}, \mathrm{Y}, \mathrm{Sc}$ e ETR por espectometria de plasma (ICP-Aes) e Rb por absorção atômica, operando como fotômetro de chama, nos laboratórios de geoquímica do Imperial College - Universidade de Londres. Th, U, Hf e Ta foram analisados por ativacão neutrônica, sendo as amostras irradiadas no reator do Imperial College e contadas nos contadores (Ge e $\mathrm{GeLi}$ ) do Natural History Museum - Londres. Nb, $\mathrm{Zr}$ e Pb foram analisados por fluorescência de raios X na Universidade Durhan - Inglaterra. Análises representativas de todas as fácies, com as respectivas normas CIPW, são mostradas nas tabelas 2,3 e 4 .

Elementos maiores As rochas do Complexo Bom Jardim mostram largo intervalo de variação de $\mathrm{SiO}_{2}(5,34 \%$ a 74,34\% em peso). A presença de clinopiroxênio e anfibólio nos sienitos e monzonitos caracteriza estas rochas como metaluminosas (Shand 1951), coincidindo com sua classificação no diagrama proposto por Debon \& Lefort (1983) (Fig. 3 ), enquanto os granitos são claramente peraluminosos, sempre apresentado coríndon normativo.

Os teores de $\mathrm{K}_{2} \mathrm{O}$ nos sienitos e monzonitos são elevados (4,6 - 8,2\% em peso) e sempre maiores que os de $\mathrm{Na}_{2} \mathrm{O}$ ). $\mathrm{O}$ caráter shoshonítico destas rochas tem sido demonstrado por Guimarães et al (1988) e Guimarães (1989).

Os óxidos dos elementos maiores foram projetados com base no índice de diferenciação (D.I.) de Thorton \& Tuttle (1969) (Fig. 4). Este índice foi preferido a uma projeção mais convencional corno a de Harker, por exemplo, devido a restrita variação de $\mathrm{SiO}_{2}$ na suíte sienito-monzonito. Os membros das fácies sienitos-monzonitos mostram valores de D.I. variando continuamente de 54 a 84 , enquanto os granitos formam discreto grupo de valores no intervalo 85 a 94 .

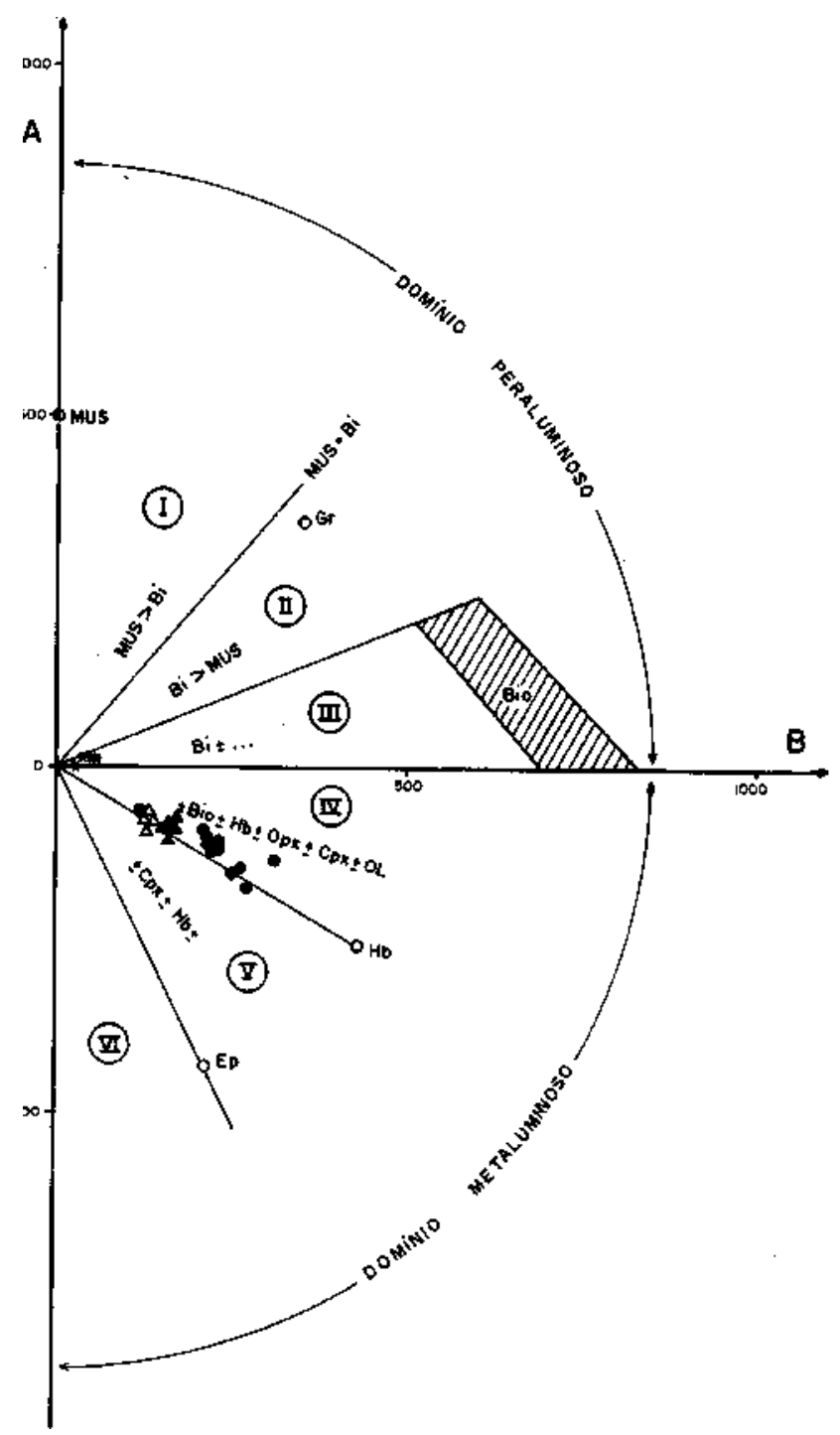

Figura 3 - Classificação das rochas do Complexo Bom Jardim no diagrama de Debon \& Lefort (1981). Símbolos como na figura 2

Figure 3 - Classification of the rocks from the Bom Jardim complex after Debon \& Lefort (1981). Symbols as in figure 2

$\mathrm{Na}$ projeção de $\mathrm{Al} \mathrm{O}_{3}, \mathrm{~K}_{2} \mathrm{O}, \mathrm{Na}_{2} \mathrm{O}$ e $\mathrm{TiO}_{2}$ versus D.I., os granitos (GRF) estão fora do /rewí/principal apresentado pela suite sienito-monzonito. Correlações negativas são observadas para $\mathrm{CaO}, \mathrm{MgO}, \mathrm{FeO}(\mathrm{t})$, TiO e $\mathrm{P}_{2} \mathrm{O}_{5}$ e correlações positivas para $\mathrm{K}_{2} \mathrm{O}$. Correlações definidas não foram observadas para $\mathrm{Na}_{2} \mathrm{O}$ e $\mathrm{Al}_{2} \mathrm{O}$. Os diagramas de variação (Fig. 4) sugerem que a fácies $\mathrm{SEG}$ não corresponde à diferenciação simples de termos mais básicos.

Modelamento da variação dos elementos maiores, utilizando o método dos mínimos quadrados, foi usado para a suíte sienito-monzonito, excluindo as fácies SEG e GRF, desde que a geoquímica de GRF aponta outra fonte de geração, e SEG uma fácies cumulática. O programa utilizado (Saunders, comunicação pessoal) segue relação simples:

Composição do magma parental = fases extraídas do liquidus + composição do líquido residual.

Conhecendo-se a composição das fases que estão sendo fracionadas, assim como a composição do magma parental e residual, as proporções relativas das fases extraídas e a quantidade de líquido residual podem ser calculadas. O 
Tabela 2 - Concentração de elementos maiores (\%peso) e traços (ppm) de amostras representativas das fades principais do Complexo

Bom Jardim

Table 2 -Majorelements( $($ veight $\%$ ) and trace elements concentrations (ppm) of representative samples from the Bom Jardim Complex major facies

\begin{tabular}{|c|c|c|c|c|c|c|c|c|c|c|c|c|c|c|c|c|}
\hline Fricles & & & & & Ma & & & & & & & & SM & & & \\
\hline AMOSTKA & 199 & 282 & b & 200 & 144 & 344 & 75 & 90 & 8 & 304 & $n$ & 53 & 48. & $\mathbf{2 6 2}$ & की & $m$ \\
\hline $\mathrm{S}_{\mathrm{NO}_{2}}$ & 52,38 & 55,03 & 56,59 & 5,62 & 50,0 & 54,35 & 55,64 & 5404 & $56,04:$ & $6 L, 11$. & 59,18 & 61,6 & 60.17 & 6242 & 61,69 & 59,63 \\
\hline TiO2 & 1,13 & 198 & 1,92 & 1,9 & L.99 & 1,056 & a.91 & 1,00 & 0,8 & 072 & $0,7$. & 0.6 & an: & ass. & 0,60 & 074 \\
\hline $\mathrm{Al}_{2} \mathrm{O}_{3}$ & 14,50 & 15,06 & 15,43 & 15,46 & $14,0 \mathrm{an}$ & 14,4 & $15, \pi$ & 16,0 & 15,22 & 14,62 & 15,59 & 13,10 & 15,25 & 15,18 & 15,10 & 15,46 \\
\hline $\mathrm{Fe}_{2} \mathrm{O}_{3}(\mathrm{~T})$ & 7,28 & 6,57 & 6,00 & 6,2 & 764 & 0,64 & 5,87 & 622 & 6.53. & 462 & 5,00 & 4,39 & 4,80 & 1.84 & 4,56 & 481 \\
\hline Mno & 0,10 & 0,10 & 0,0 & 0,09 & 0,12 & 0,10 & 0,08 & 0,07 & 0,10 & 0,07 & $0,09 t$ & 40 & 0,07 & 0,05 & 0.04 & 0,06 \\
\hline $\mathrm{MgO}$ & 4,51 & 5,51 & $5,0,0$ & 5,35 & 808 & 6.12 & 5,060 & 5.53 & 5,52 & 3,93 & 3,8 & 3,76 & 421. & 2,9 & 3,76 & 3,92 \\
\hline $\mathrm{CO}$ & 6,74 & 5,50 & 5,06 & $5,4,4$ & 648 & 612 & 458 & 5,14 & 5,34 & 3,44 & 3,69 & 3,40 & 3,67 & 2,80 & $3, \infty$ & 3.50 \\
\hline $\mathrm{Na} \geq \mathrm{O}$ & 3.41] & 3,79 & 3,86 & 3,59 & 3,11 & 3,65 & $3, \pi$ & 3,87 & 3,60 & $3, \pi$ & 3,95 & 3,65 & $3, \pi$ & 4,09 & 3,65 & 3,84 \\
\hline $\mathrm{K} 2 \mathrm{O}$ & 165. & 4,93 & 5,11 & 5,23 & 3,36 & 490 & 5,71 & 5,55 & 5,03 & 6.18: & 428. & 4.14 & 6,06 & 6,14 & 5,9 & 6.17 \\
\hline $\mathrm{P}_{20} \mathrm{O}_{5}$ & 0,98 & 0,68 & 0,03 & 07 & 0,47 & 0,74 & n.59 & 0,65 & 0,70 & 0.46 . & asol & Q.41 & $0, \phi$ & 0,36 & 0.41 & a.45 \\
\hline P.F. & a90 & 0,75 & Q50] & 0,49 & 0,57 & 0,88 & n.56 & 465 & 0,61 & $0 ; 2$ & 0,49 & 0,39 & a.39 & 0,65 & 0,65 & ast \\
\hline TOTAL" & 99,25 & 99,49 & 99,75 & 99,80 & $\$ \$, 65$ & 100,13 & 99,00 & 98,45 & 99,89 & 9,99 & 100004 & 9,47 & 100,07 & 9049 & 100,00 & 998 \\
\hline$s r$ & 2226 & 1625 & $15 n$ & 1799 & 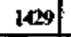 & 1810 & 1711 & 1853 & 1729 & 1248 & 1457 & 1538 & 1492 & I187 & 1238 & 1494 \\
\hline $\mathrm{Ba}$ & 3786 & 3167 & 2976 & 3700 & 1764 & 3475 & 3367 & 3789 & 3401 & 272 & 3074 & $30 \div 0$ & 3073 & 2500 & 257 & 3041 \\
\hline Rb & 125 & 154 & 168 & 144 & 12 & 19 & 150 & 150 & 133 & 1900 & 190 & 14 & 193 & 188 . & 184 & 200 \\
\hline $\mathbf{u}$ & 1,1 & 1,1 & 3,6 & 0,82 & 20 & Q99 & 27 & 0,6 & nud & 4.1 & 23 & 2,2 & n.d. & 2,3 & n.d. & nd \\
\hline Th & $5 B$ & 201 & 12,4 & 40. & 3,1 & 10,4 & 15,2 & 28 & n.u. & $2 \mathrm{~L}, 1$ & 23,8 & 16,7 & n.d. & 16,7 & n.d. & nd \\
\hline or & 320 & 220 & 210 & 20 & 430 & 240 & 225 & $2 * 0$ & 230 & 180 & 165 & 16 & 160 & 150 & 190 & 180 \\
\hline $\mathrm{Ni}$ & 190 & 120 & 210 & 110 & 250 & $16 \theta$ & 120 & 1300 & 120 & 100 & 90 & $\mathbf{0}$ & 90 & 70 & 100 & 100 \\
\hline $\mathbf{z}$ & $1 \neq 0$ & 230 & 250 & 330 & 230 & 170 & 400 & 250 & 270 & 300 & 360 & 300 & 340 & 200 & 230 & 360 \\
\hline $\mathrm{HI}$ & n.d. & $1 a_{1}$ & 9,1 & 87 & 7,0 & 123 & 9,9 & 28 & rad & 10,7 & 12,4 & 10,1 & . & $\mathrm{nt}$ & n.d & nd. \\
\hline$\tau$ & n.d. & $a, 70$ & L,48 & 0,0 & 0,83 & 0,58 & 0,75 & 0,48 & nad & $1, \$ 9$ & $0 ; 00$ & 0,86 & - & 1,008 & ad. & $\mathrm{na}$ \\
\hline $\mathrm{Nb}$ & 15,0 & 15,0 & 21,0 & 12,0 & 1,7 & 1,7 & 16,0 & 16,8 & 9,6 & 200 & 240 & 17,0 & 180 & 1,6 & n.d. & nd \\
\hline $\mathrm{Pb}$ & 28 & 38 & nd. & 30 & 21 & n.d. & M.d. & 31 & ad. & $\$ 1$ & n.d. & 43 & D.d. & 44 & n.d & nd \\
\hline
\end{tabular}

\begin{tabular}{|c|c|c|c|c|c|c|c|c|c|c|c|c|}
\hline FACIES & & & $\mathbf{s}$ & & & & EG & & & GRA & & \\
\hline AMOSTRA & 160 & 10 & 25 & 323 & 4 & $5-4$ & 23 & 4 & 43 & 223 & 36 & 328 \\
\hline $\mathrm{siO}_{2}$ & 6271 & 61,54 & 61,10 & 61,61 & 61,52 & \$R, 4 & $\$ 1,12$ & 61,90 & $\mathbf{2} ; \mathbf{6} \mathbf{6}$ & 72,56 & 71,7 & 69,8 \\
\hline $\mathrm{TTO}_{2}$ & 0,77 & 4.82 & 0,04 & 0,67 & 0,80 & 1,06 & (999) & 0,00 & 0,24 & 0,27 & 0,0 & Q.54 \\
\hline $\mathrm{A} 2 \mathrm{2} \mathrm{O}_{3}$ & 15,16 & 14,96 & 14,99 & $14 \pi$ & 16,04 & 1494 & is, 90 & 16,29 & 14,00 & 14,52 & 14,65 & $\mathbf{1 4 , 5 5}$ \\
\hline $\mathrm{F}=203(\mathrm{~T})$ & 4,66 & 4,99 & 4,67 & 4,75 & 4,99 & 5,80 & 455 & 3,43 & $1,8 \%$ & 1,74 & 2,2 & 291 \\
\hline $\mathrm{MnO}$ & 0,06 & 0,07 & 0,07 & 0,06 & 0,06 & 0,06 & 006 & 0,04 & 0,01 & 0,04 & 0,01 & 0,04 \\
\hline $\mathrm{MgO}$ & 2,38 & 2,89 & 2,79 & 3,11 & 271 & $3,4,45$ & 20 & $\mathbf{1 , 8 1}$ & $0 \leq 2$ & 0,53 & 0,68 & 0,55 \\
\hline $\mathrm{CoO}$ & 266 & 2,86 & 278 & 2,83 & $2,6 \theta$ & 3,55 & 2,0 & 2,18 & 1,42 & $\mathbf{2 . 4 3}$ & 1,56 & 1,74 \\
\hline $\mathrm{NazO}$ & 4,11 & 3,96 & x\$ & 3,75 & 4,32 & 3,74 & 4,35 & 3,92 & 3.72 & 4,39 & 3,66 & 3,41 \\
\hline $\mathrm{k} \infty \mathrm{O}$ & 685 & 6,65 & 480 & 4,7) & 467 & 7,41 & 7,45 & 8,25 & 4,37 & 4,4 & 5,09 & 5,65 \\
\hline $\mathrm{P}_{2} \mathrm{OS}_{3}$ & 0,44 & 0,47 & 0,43 & 0,41 & Q44 & 0,63 & 4,39 & 0.34 & 0,12 & 0,11 & 0,14 & 0,21 \\
\hline P.F. & 4,3 & 0,20 & 0,15 & 0,30 & 0,13 & a,26 & (4,32 & 0,30 & as4 & 0,34 & 0,41 & 0,39 \\
\hline TOTAL" & 100,39 & 99,92 & 9,06 & 90,56 & 100,31 & 9,83 & 100,30 & $99, x$ & 100,20 & $190,-11$ & 100,94 & 100,64 \\
\hline Sr & 1331 & 1199 & 1130 & 1236 & 1189 & 1226 & 778 & 1186 & 735 & 445 & 854 & 911 \\
\hline Ba & 2744 & 2558 & 2441 & 2627 & 2477 & 2785 & 2004 & 3000 & 1489 & 760 & 2173 & 2410 \\
\hline $\mathbf{R} \mathbf{b}$ & $2 x 0$ & 200 & 276 & 250 & 245 & 265 & 300 & 285 & $1+0$ & 218 & 100 & 183 \\
\hline $\mathbf{u}$ & 3,67 & 3,3 & 4,5 & 5,9 & 3,0 & nud. & 2.93 & nad. & n.d. & 46 & n.d. & 2,4 \\
\hline Th & 64,6 & 4.5 & $+0,2$ & 61,4 & nad & nd. & 17,4 & ad. & 4.8 & 19.7 & 7,7 & 22 \\
\hline $\mathrm{Cr}$ & 60 & 110 & 90 & 120 & 100 & $\$ 10$ & 80 & 55 & 30 & - & 30 & 20 \\
\hline $\mathrm{Ni}$ & 50 & 40 & 40 & 60 & 50 & 60 & 20 & $\$$ & 20 & . & - & 15 \\
\hline Zr & 560 & $5 \pi 0$ & 530 & 360 & 640 & 640 & 310 & 500 & 168 & 130 & 100 & 240 \\
\hline $\mathrm{HE}$ & 20,2 & 17, & 14.9 & n.d. & n.L. & n.d. & 10,0 & n.d. & n.d & 4,8 & n.d. & 6.7 \\
\hline$T_{0}$ & 2,4 & 1,38 & 1,48 & 240 & 1.4 & a.d. & 1.53 & n.d. & n.d. & Q61 & nd. & 1,3 \\
\hline Nb: & 34,0 & 31,0 & 27,0 & 15,7 & 42,1 & n.d. & 27,0 & n.d. & 40 & 10,0 & 5,7 & 15,0 \\
\hline $\mathrm{Pb}$ & 55 & 31 & 60 & 59 & n.d. & n.d. & 40 & a.d & 38 & 45 & 37 & 35 \\
\hline
\end{tabular}


Tabela 3 - Composição normativa (CIPW) de amostras representativas das fácies principais do Complexo Bom Jardim Table 3 - Normative composition (CIPW) of representative samples from the Bom Jardim complex major facies

\begin{tabular}{|c|c|c|c|c|c|c|c|c|c|c|c|c|c|c|c|c|}
\hline PACIFS & & & & & Mo & & & & & & & & SM & & & \\
\hline AMOSTRA & 199 & 283 & 1 & $2 \infty$ & 14 & 34 & $\pi$ & $\$ 0$ & B & 305 & 27 & 53 & 48 & 262 & 47 & 107 \\
\hline 0 & .1 & $\bullet$ & $\cdot$ & $\cdot$ & $\theta$ & $\cdot$ & . & . & & 3,97 & 0,14 & 3,00 & $2,0.4$ & 6,13 & 5,35 & 1,56 \\
\hline or & 27,28 & $20 \%$ & 30,06 & 31,17 & 34,18 & 25,95 & 33,96 & 32,4 & $\$ 54$ & 34,74 & 37,30 & 35,07 & 35,63 & 14. 18 & 36,18 & 34,74 \\
\hline 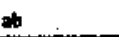 & 24,35 & $31, \omega$ & 3252 & 30,42 & 2202 & 2897 & 31.40 & $2 \times 55$ & 30,42 & 31,94 & 33,57 & 3400 & 31,47 & $-4,62$ & 30,94 & 32.52 \\
\hline$m$ & 10,57 & 9.74 & 9,74 & 10,57 & 807 & 10,02 & $\sin$ & 10,20 & 10,57 & 4,45 & a.12 & 6,40 & 7,23 & $5,0 t$ & 0,68 & 0,68 \\
\hline at & 1,35 & & $\cdot$ & & 2041 & 1,07 & $0,32]$ & $3,2.2$ & $\cdot$ & . & . & . & $\therefore$ & . & - & \\
\hline $\mathrm{HH}$ &. & 200 & 7.47 & 4.17 & & - & & & 8.50 & 9,30 & 9.7 & 9,01 & 11,03 & $7.6,1$ & 9.87 & 10,044 \\
\hline D & 13,12 & 10,38 & 9,29 & 920 & 9.94 & 12,58 & B.19: & 856 & 900 & 7,81 & a,83 & a.22] & 4.48 & 4,2 & 0,04 & 0.25 \\
\hline 어 & 11,38 & 4,7 & 3,40 & $6, B$ & $i 2,64$ & 10,53 & 9,4 & 10,45 & 3,28 & ano & & & & & & \\
\hline $\mathbf{a x}$ & 255 & 2,32 & 255 & 232 & 200 & 232 & 2,32 & 2,32 & $2 \pi$ & 200 & 232 & 200 & 200 & 1,62 & 1,85 & 2116 \\
\hline 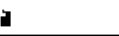 & 212 & 1,82 & 1,82 & 1,0 & 152 & 1,97 & 1,67 & 1,9 & 1,82 & 1,37 & 1,52 & 1,37 & 1,37 & 1,000 & 1,37 & 1,37 \\
\hline$\varphi$ & 2.17 & $\mathrm{~L}, \mathrm{~s}$ & 1,24 & 1,55 & 1,55 & 1,55 & 1,24 & L.55 & 1,55 & 0,93 & 1,24 & $0,9]$ & 0,93 & 0,93 & 0,93 & 0,43 \\
\hline DN & 54,4 & (m)14) & -258 & $n, 1,54$ & (1).1.1. & $58 \%$ & $\sin x$ & 6269 & \$90.92 & 727 & $7,, 01$ & $72 \mathrm{~lm}$ & 470 & 79,42 & 7247 & $70, k$ \\
\hline
\end{tabular}

\begin{tabular}{|c|c|c|c|c|c|c|c|c|c|c|c|c|}
\hline \multirow{2}{*}{\begin{tabular}{|c|} 
FACIES \\
AMOSHRA \\
\end{tabular}} & \multicolumn{5}{|c|}{ LS } & \multicolumn{3}{|c|}{ SEG } & \multicolumn{4}{|c|}{ oHANTITs } \\
\hline & 100 & 10 & 25 & (21) & 49 & 54 & 27 & $\omega$ & 43 & 22 & 36 & $12 k$ \\
\hline $\mathbf{q}$ & 5.11 & 3,97 & 3.60 & $4, \phi \theta$ & 204 &. & 0,42 & 2.94 & $29 \%$ & $25, \mathbf{2} 2$ & 26,66 & 23,41 \\
\hline or & 9064 & 34.52 & +08 & 39,52 & 3,52 & 43,98 & 43,98 & +49 & 27,28 & $2 n \pi$ & 30,06 & 39,41 \\
\hline$\Delta$ & 34,62 & 33,57 & 33,57 & 31,99 & 34,71 & 31,47 & 3671 & 33,04 & 31,47 & 37,24 & 30,94 & $2 \pi / 5$ \\
\hline$m$ & $2 \pi$ & 3,24 & 3,06 & 3,62 & 4,45 & 1,95 & 1,95 & 250 & 6.03 & 603 & 68 & 7,70 \\
\hline$m$ &. &. &. &. & - & - & . & + & $*$ & - & T & . \\
\hline c &. &. &. &. & . &. & $=$ & . & 0.65 & 0,14 & 0,65 & 0,00 \\
\hline Hi & 5,51 & 7,13 & 657 & 811 & 797 & 228 & 3,41 & $3, \infty$ & $\mathbf{L , 9 7}$ & 2.34 & 250 & 294 \\
\hline Di & 606 & 6,50 & 6,50 & 6,06 & 494 & 8,80 & 5,84 & 5.15 & + & - & . & \\
\hline a & - & - &. &. &. & 0,95 & - & $\therefore$ & - &. &. & - \\
\hline $\mathbf{m t}$ & 2,32 & 2,32 & 2,32 & 2,08 & 2,32 & $2, \pi 9$ & 2,06 & 240 & 1,16 & 0.8 & 1,39 & 208 \\
\hline il & 1.52 & 1,52 & 1,67 & 1,21 & 1,52 & 1,99 & 1,82 & 1,52 & 0,46 & 0.4 & 0.76 & $1,0 \%$ \\
\hline ap & 0,93 & $0^{93}$ & 0,93 & 0,43 & 0,95 & 1,55 & 0,93 & 0,02 & $a 31$ & 0,31 & 0,31 & (4.31 \\
\hline Di & 80,37 & $\pi, 10$ & $\pi, 2 s$ & 76,20 & 8,27 & 75,45 & 81,11 & 89,87 & 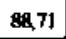 & 89,72 & $87,6 \mathrm{nt}$ & $85.6 \%$ \\
\hline
\end{tabular}

Tabela 4 - Concentração de elementos terras raras (ETR) em ppm, de amostras representativas das fácies principais do Complexo Bom Jardim

Table 4 - Concentration of rare earth elements (REE) in ppm of representative sample from the Bom Jardim complex major facies

\begin{tabular}{|c|c|c|c|c|c|c|c|c|c|c|c|c|}
\hline & ه & c. & $\mathbf{P}_{\boldsymbol{T}}$ & Nd & Sor & Eu & $G d$ & Dy & Er & $\mathrm{Yb}_{b}$ & L, & $\mathbf{Y}$ \\
\hline 144 & 55,0 & $133, \mathbf{4}$ & 140 & 55,5 & h9 & 26 & 64 & 39 & $1, \mathrm{~B}$ & 1,4 & $\begin{array}{r}0,2 \\
\end{array}$ & 187 \\
\hline 34 & 162,6 & 2043 & 28,2 & 902 & 15,8 & 4,0 & 109 & 5,9 & 24 & 1.7 & 0,2 & 228 \\
\hline 200 & $\pi, 6$ & 135,3 & 19,3 & $\mathbf{n g}$ & 11,7 & 3,3 & 7.8 & 4,2 & 21 & 1.3 & 0,2 & 17,2 \\
\hline 14 & 99,1 & $17 \times 3$ & 20,6 & 70 & 11,4 & 26 & 82 & 4.7 & 22 & 1.6 & 02 & 190 \\
\hline 54 & 106,8 & 205,0 & 24,1 & 86,2 & 14,0 & 3,3 & 100 & 5,4 & 25 & 1.7 & 0.2 & 21,1 \\
\hline 4 & 67,0 & 1325 & 16.2 & 648 & 9,0 & 24 & 6,5 & 3,8 & $\mathbf{1 , B}$ & 1,3 & 0.2 & 14,8 \\
\hline 4 & 78,8 & 145,3 & 16,6 & 61,2 & 9,8 & 27 & 69 & 3,6 & 1,6 & 1,2 & $\mathbf{4 2}$ & 14.4 \\
\hline $2 m$ & 4,2 & 84 & nd & 280 & 4,1 & 48 & 0,8 & $T \mathrm{~b}=0,34$ & $\operatorname{Tn}=0,1$ & 0,5 & 0,06 & 7,0 \\
\hline 36 & 32,9 & $55 . j$ & 5,9 & 21,4 & 27 & 2.8 & 4,9 & 1,0 & 4.5 & 0,3 & 0,06 & 3,8 \\
\hline 0 & 227 & 37.2 & $4 ?$ & $13,7$. & 1,9 & 13 & 1.1 & 0.7 & 0.3 & 0,3 & 0,04 & 4,2 \\
\hline
\end{tabular}

programa permite o máximo de 10 óxidos componentes e nove fases minerais extraídas simultaneamente. Quatro estágios intermediários de fracionamento, dentro do trendsienitomonzonito, foram escolhidos: Estágio 1. 53,02 a 56,59\% de $\mathrm{SiO}$; Estágio 2. de 56,59 a 59,63\% de $\mathrm{SiO}_{2}$; Estágio 3.59,63 a $61,69 \%$ de $\mathrm{SiO}_{2}$; Estágio 4. 61,69 a 62,71\% de $\mathrm{SiO}_{2}$. O sumário dos resultados é dado na tabela 5 , juntamente com a qualidade da reta de regressão linear (R2).

Os resultados do modelamento mostram que durante o estágio I (evolução da fácies SMG) os principais minerais extraídos são as duas fases pobres em $\mathrm{SiO}_{2}$ : anfibólio e biotita. A quantidade combinada destes dois minerais é quase duas vezes a quantidade de plagioclásio. Feldspato potássico não foi fase extraída durante o fracionamento inicial.

A composição inicial do líquido para o estágio 2 foi escolhida para coincidir com o ponto de inflexão (D.I. $=70$ ) nos diagramas de variação mostrados na figura 4. Durante o estágio 2, plagioclásio e anfibólio permaneceram como as principais fases fracionadas. Biotita diminui significativamente e feldspato potássico apareceu pela primeira vez em 
Tabela 5 - Resultados do modelamento das variações nas concentrações dos elementos maiores, pelo método dos mínimos quadrados dentro do Complexo Bom Jardim

Table 5 - Results of the least squares mixiogsolution forthe modelling of the variations in major elements concentrations within the Bom Jardim complex

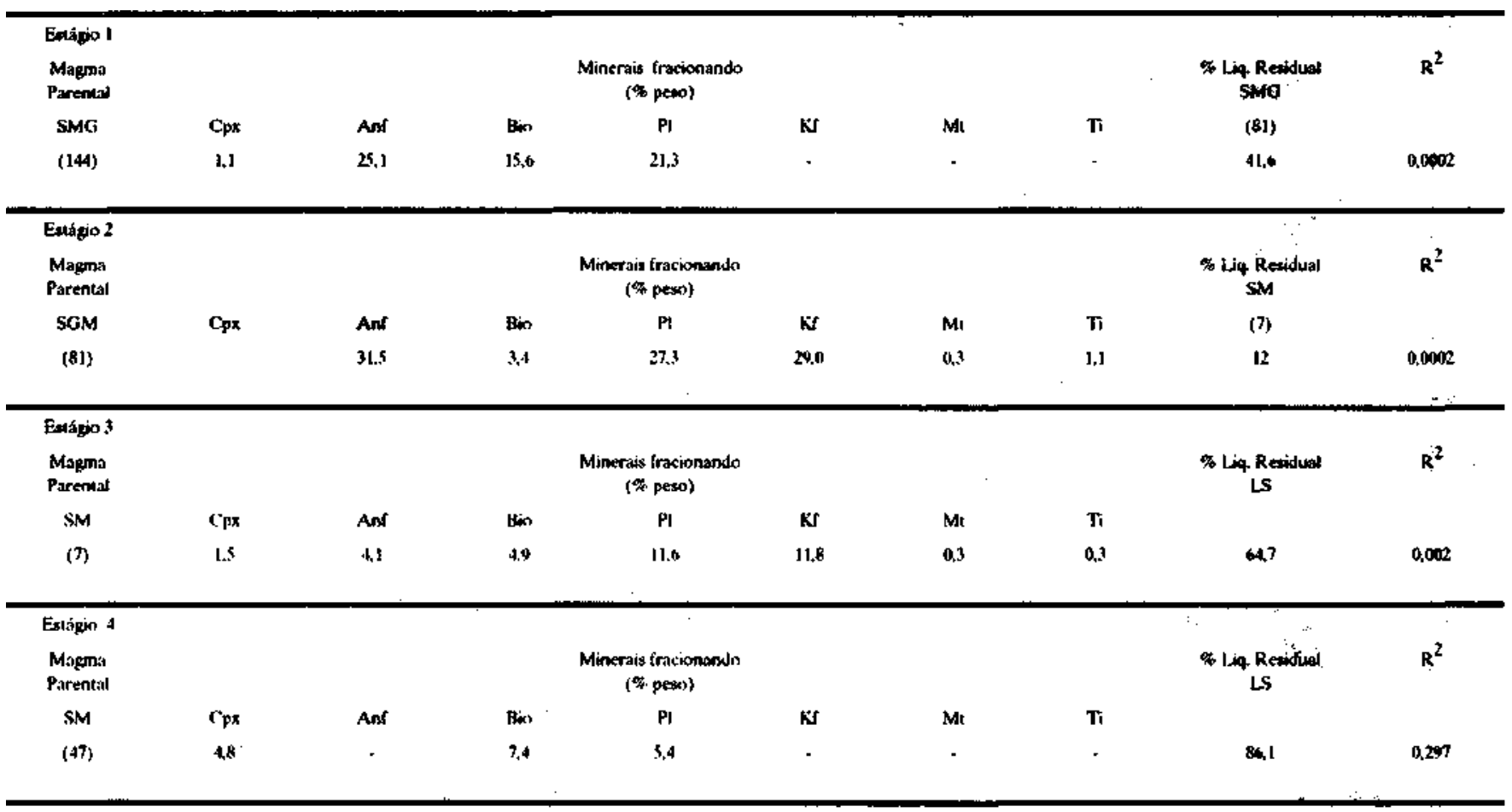

quantidade igual ao plagioclásio e anfibólio. À mais significativa diferença entre os estágios dois e três é o decréscimo no total de sólidos extraídos que continua dentro do estágio 4 . No estágio final, clinopiroxênio, anfibólio e biotita são os únicos minerais fracionados. A qualidade da reta de regressão no estágio final é inferior à qualidade obtida nos estágios anteriores, e precauções devem ser tidas ao interpretar os valores obtidos. A diferença de composição entre o magma parental e o residual é muito pequena, e isto, juntamente com a possibilidade do magma se comportar nos estágios finais mais como crystal mush que como fase líquida, poderia ter diminuído a qualidade da reta de regressão.

Elemento traços As rochas do Complexo Bom Jardim mostram elevados teores de Ba (4.389 e 2.060 ppm), Sr (2.198 a 1.015 ppm), Th (2,8 a 61,4 ppm), U (0,6 a 6,0 ppm) e $\mathrm{Pb}(22$ a $60 \mathrm{ppm})$; teores médios de $\mathrm{Rb}$ (120 a $300 \mathrm{ppm})$. Nb apresenta teores inferiores a $20 \mathrm{ppm}$ na fácies menos diferenciada (Tab. 3). Ba e Sr comportaram-se, em geral, de forma compatível durante a evolução do complexo, o oposto foi observado no comportamento de Rb e Cs (Fig. 5). Isto parece indicar que a porcentagem de biotita fracionada foi pequena, sendo compensada pelo fracionamentò de minerais com alta incompatibilidade por $\mathrm{Rb}$, como anfibólio, piroxênio e feldspato, de acordo com os Kds fornecidos por Gill (1978) para rochas de composições intermediárias. A variação de $\mathrm{Sr}$ com D.I. (Fig. 5) mostra que o trend pode ser dividido em quatro componentes. A evolução da fácies SMG mostra um trend horizontal. O mesmo é observado para LS e SEG. A fácies SM mostra correlação negativa entre Sr e D.I.; os granitos formam grupo à parte. $\mathrm{O}$ trend horizontal na fácies SMG é perfeitamente explicado pelo fracionamentò de biotita e anfibólio (Kd para $\mathrm{Sr}<1,0)$, enquanto a correlação negativa observada em SM é largamente controlada pela compatibilidade do $\mathrm{Sr}$ em fases como plagioclásio e feldspato potássico. $\mathrm{Na}$ fácies LS, o trend horizontal parece refletir o comportamento do magma como crystal mush, enquanto em SEG reflete o caráter cumulático desta fácies.

As razões $\mathrm{Rb} / \mathrm{Sr}$, obtidas no Complexo Bom Jardim (0,05 a 0,30$)$, não comparáveis àquelas determinadas para os monzonitos de afinidades shoshoníticas do batólito WhiteInyo Rage, Califórnia (Sylvester et al. 1978), e os granitóides pré- a médio silurianos da região norte da Escócia (Brown et ai. 1981). Porém, são baixas quando comparadas a típicas suítes cálcio-alcalinas, com teores similares de $\mathrm{SiO}_{2}$, como, por exemplo, o batólito costeiro Peruano (Atherton \& Sanderson

1985) e o batólito de Sierra Nevada (Bateman \& Dodge 1970).

Segundo Condie (1973), os teores de Rb e Sr em rochas ígneas permitem determinar a espessura crustal. Como indicado na figura 6 , os teores de $\mathrm{Rb}$ e $\mathrm{Sr}$ nas rochas do Complexo Bom Jardim indicam que as mesmas foram geradas em profundidades superiores a $30 \mathrm{~km}$. Olade (1976) concluiu que a razão $\mathrm{Rb} / \mathrm{Sr}$ reflete a origem das rochas graníticas mais do que os efeitos de fracionamentò mineral, e que rochas com razões $\mathrm{Rb} / \mathrm{Sr}$ inferiores a 0,1 são normalmente associadas a origem mantélica; valores superiores a 0,25 , a rochas geradas por fusão crustal. Mesmo considerando que a razão $\mathrm{Rb} / \mathrm{Sr}$ para rochas da crosta superior tem aumentado desde o Arqueano até os nossos dias, de 0,08 para 0,3 (Taylor \& MacLennan 1985), ps valores inferiores a 0,09 determinados rias rochas das fácies menos evoluídas do Complexo Bom Jardim, parecem refletir origem mantélica. Hanson (1978) e Hart \& Allégre (1980) e os valores dos coeficientes de partição (Kd) para $\mathrm{Rb}$ e Sr disponíveis na literatura sugerem que á razão $\mathrm{Rb} /$ $\mathrm{Sr}$ é influenciada por processos de fracionamentò riiiheral. Fracionamentò de anfíbólio, clinopiroxênio, plagioclásio e feldspato potássico (com $\mathrm{Kd}$ para $\mathrm{Rb}<1,0$ e feídspato potássico e plagioclásio com valores de $\mathrm{Kd}$ para $\mathrm{Sr}>1,0$, segundo Gill (1978) favorecerá o aumento da razão Rb/Sr nó líquido. A projeção das razões $\mathrm{Rb} / \mathrm{Sr}$, com o índice de diferenciação para rochas do complexo (Fig. 7), substancia a influência de possíveis processos de fracionamentò ria razão $\mathrm{Rb} / \mathrm{Sr}$.

Os teores de Th (3,0 - 64,6 ppm), U (0,6-6,0 ppm) e Pb (20 - 60 

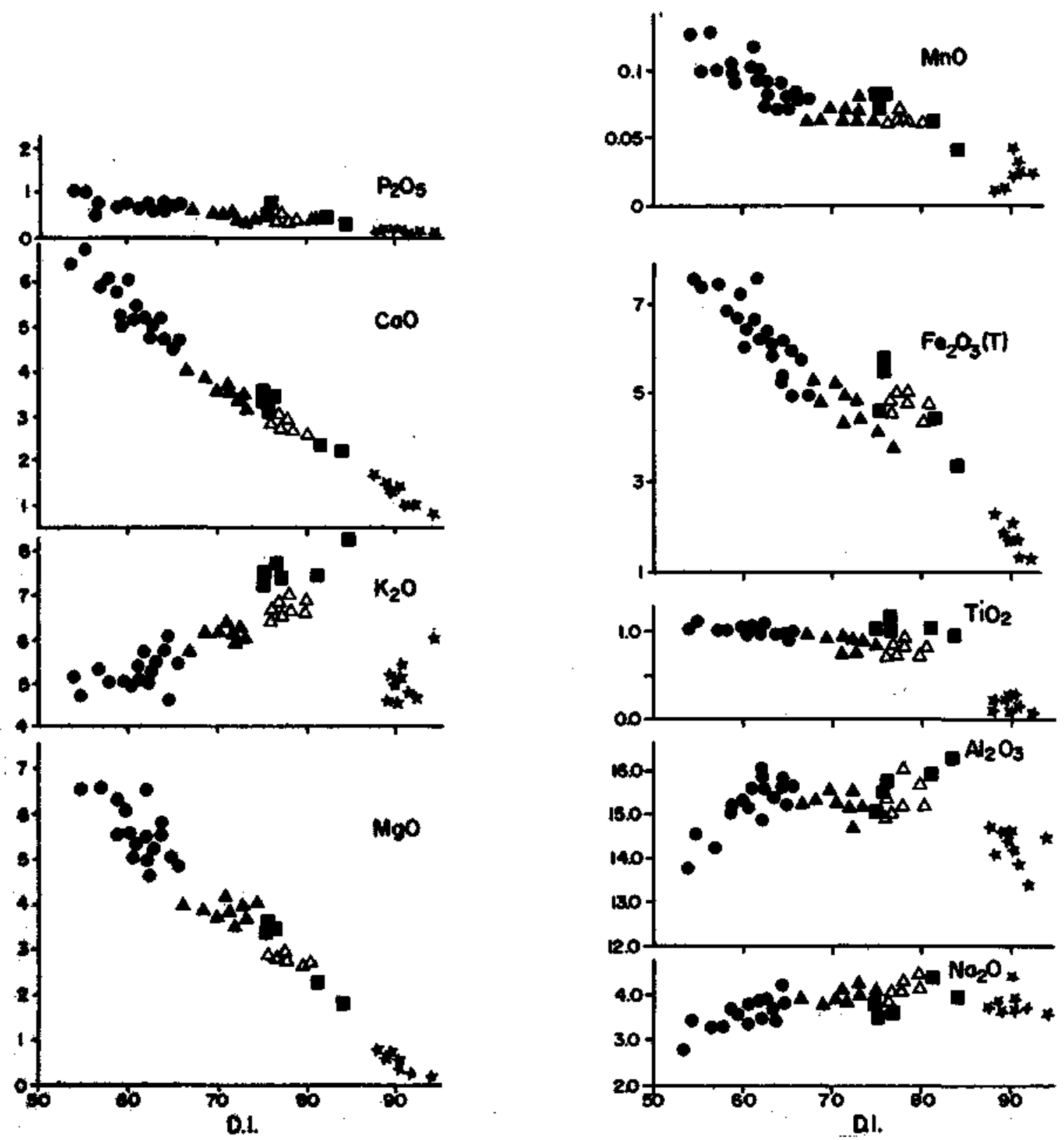

Figura 4 - Projeção dos óxidos principais vs. D.I. para as rochas do Complexo Bom Jardim. Símbolos como na figura 2 Figure 4 - Mot of the main oxides vs. D.I. Symbols as in figure 2

ppm) são elevados quando comparados aos valores médios para a crosta continental (Taylor \& MacLennan 1985).

Os teores Cr, NI e V são elevados; 450 ppm, 250 ppm e 125 ppm, respectivamente nas fácies menos diferenciadas. Vetores de fracionamento no diagrama $\mathrm{Ni}$ versus $\mathrm{Cr}$ (Fig. 8) indicam aue combinação de aproximadamente $27 \%$ de anfíbólio e $7 \%$ de biotita poderia explicar o comportamento de $\mathrm{Cr}$ e $\mathrm{Ni}$ durante a evolução do complexo. Estas porcentagens minerais são corroboradas pela petrografia.

Os teores de $\mathrm{Zr}$ nas fácies menos diferenciadas são menores que 300 ppm, sendo elevados quando comparados a típicas suítes cálcio-alcalinas, entretanto são baixos quando comparados a rochas de intervalo similar de variação em $\mathrm{SiO}_{2}$ no complexo plutônico rico em K do leste da Groenlândia (Tarney \& Saunders 1979). Zr e Hf comportaram-se de forma incompatível durante a evolução do complexo (Fig. 5), evidenciando o não-fracionamento de zircão durante a evolução magmática.

Os teores de Y obtidos são comparáveis às médias citadas por Morrison (1980) para as rochas das séries shoshoníticas.
Os valores de Y projetados contra os teores de $\mathrm{CaO}$ (Fig. 9) mostram um trend com inclinação positiva ou curvatura em "J". Lambert \& Holland (1974) referem-se a este trend como típico de rochas cálcio-alcalinas relacionadas a subducção, denominando-o de trend de séries hornblêndicas, e o interpretam como resultante de fracionamento de anfíbólio e biotita.

Elementos terras raras (ETR) Os padrões de ETR dos monzonitos e sienitos são caracterizados por razões $\mathrm{Ce} /$ Yb elevadas (25 em média), pela ausência de anomalia significativa de Eu e por forma geral côncava (Fig. 10A). Nenhuma variação signifícante da razão $\mathrm{Ce} / \mathrm{Yb}$ e na abundância dos ETR total foi observada entre as diferentes fácies sieníticas e monzoníticas, refletindo ausência de fracionamento de minerais com compatibilidade para elementos terras raras leves (ETRL) e/ou elementos terras raras pesados (ETRP), durante a evolução magmática. Isto implica que o decréscimo de $\mathrm{TiO}_{2}$ com o aumento do índice de diferenciação mostrado na figura 4 está relacionado ao fracionamento de 

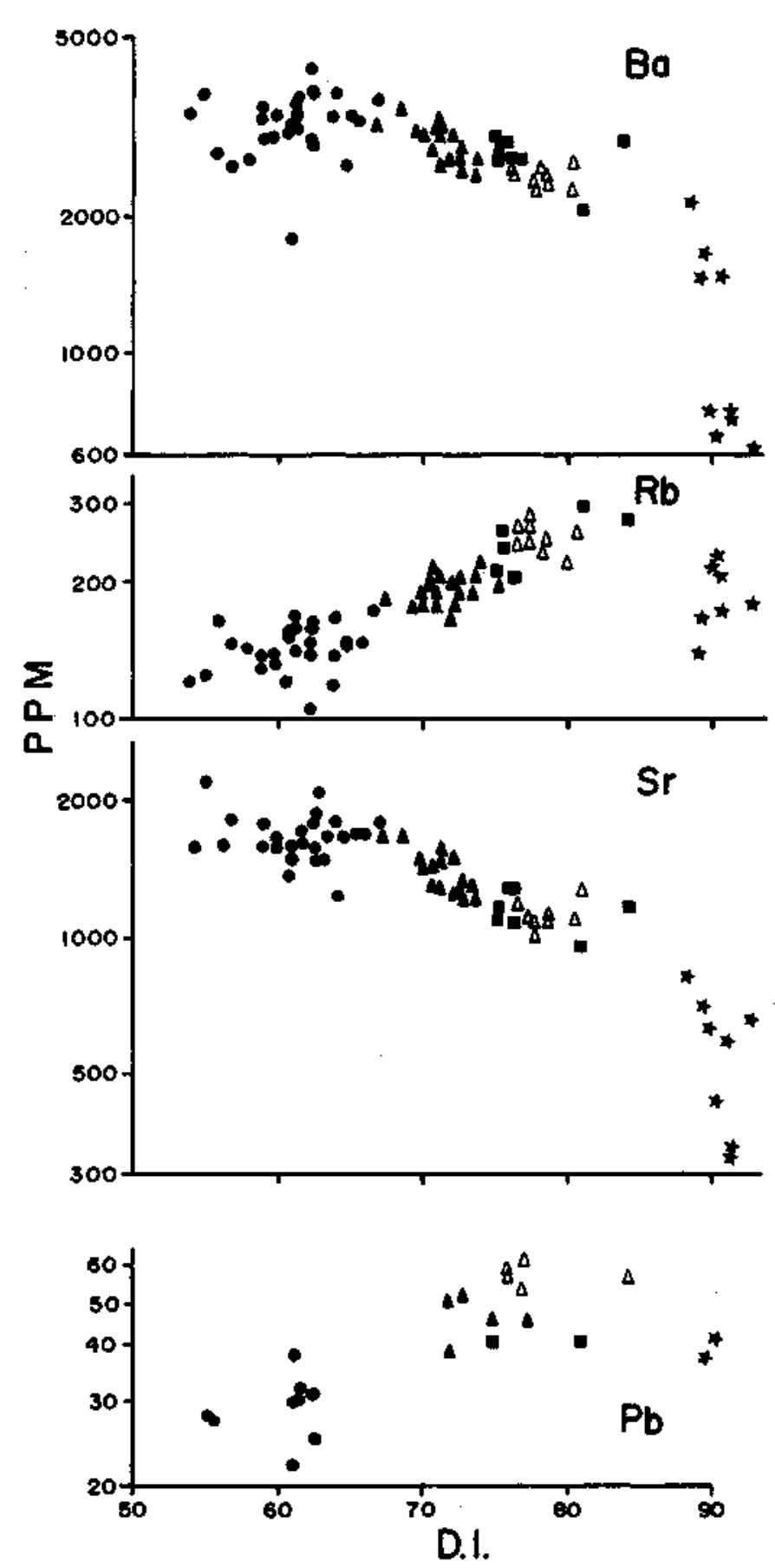

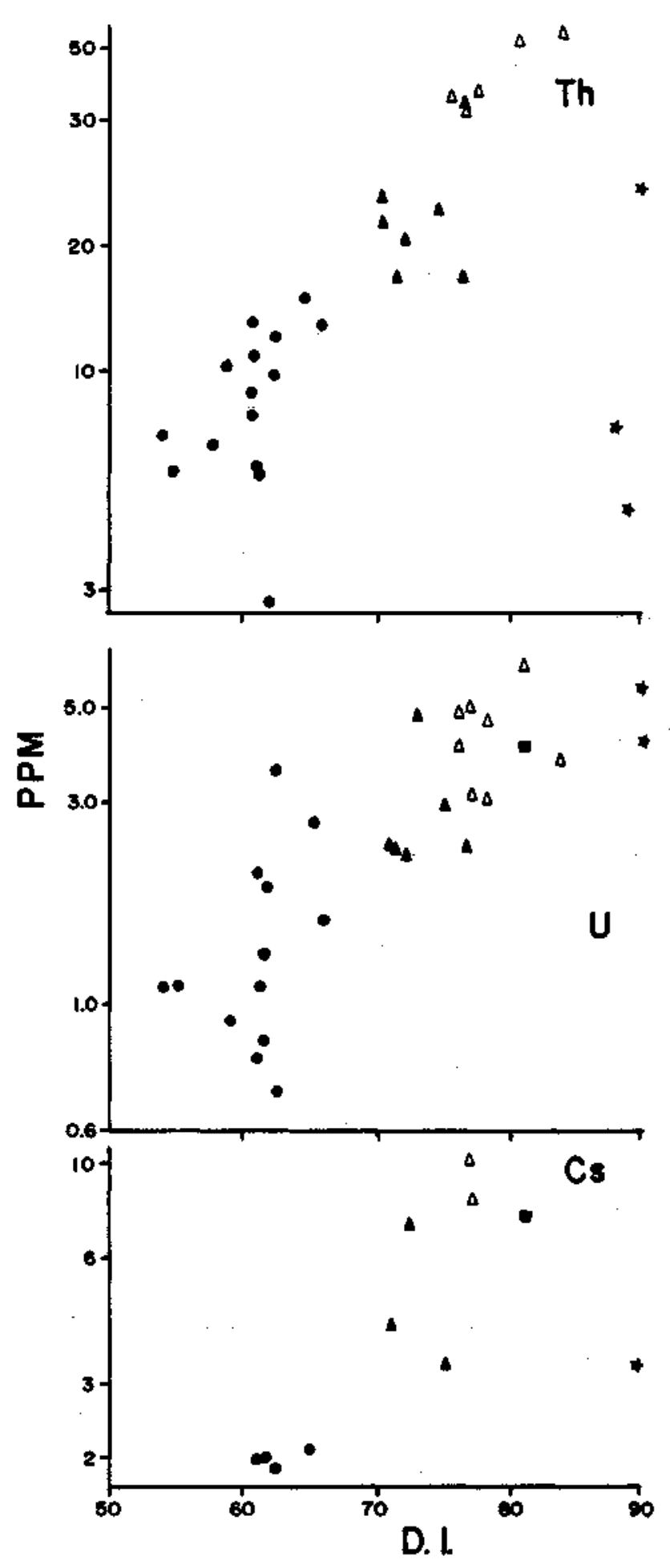

Figura 5 - Projeção de elementos traços vs. D.I. Símbolos como na figura 2

Figure 5 - Plots of trace elements vs. D.I. Symbols as in figure 2

anfibólio e biotita e não ao fracionamento de titanita. Fracionamento das fases maiores, como biotita e piroxênio não tiveram significante influência nos padrões de ETR (Fig. 11). Dy, Er e Yb são compatíveis na hornblenda. Porém, considerando $\mathrm{Kd}=4,0$ para $\mathrm{o} \mathrm{Yb}$ em hornblenda, seria necessário o fracionamento de mais de $25 \%$ de hornblenda para que o magma residual ficasse empobrecido em $\mathrm{Yb}$. Entretanto, a porcentagem necessária de hornblenda fracionada para empobrecer o líquido residual em $\mathrm{Yb}$ aumenta, quando a hornblenda está sendo fracionada juntamente com fases com
$\mathrm{Kd}<1$ para $\mathrm{Yb}$ (biotita e clinopiroxênios). $\mathrm{O}$ fracionamento de $27 \%$ de anfibolío $+7 \%$ de biotita, além de feldspatos e clinopiroxênio, respondem pela distribuição dos elementos maiores e traços no complexo, como evidenciado pela petrpgrafia(Fig. 8 e Tab. 5). Logo, a porcentagem de anfibólio fracionada também não foi suficiente para causar empobrecimento progressivo dos ETRP com a diferenciação, sugerindo que o magma que deu origem às rochas do Complexo Bom Jardim já era enriquecido em ETRL em relação aos ETRP. A ausência de anomalias de Eu nos membros menos 


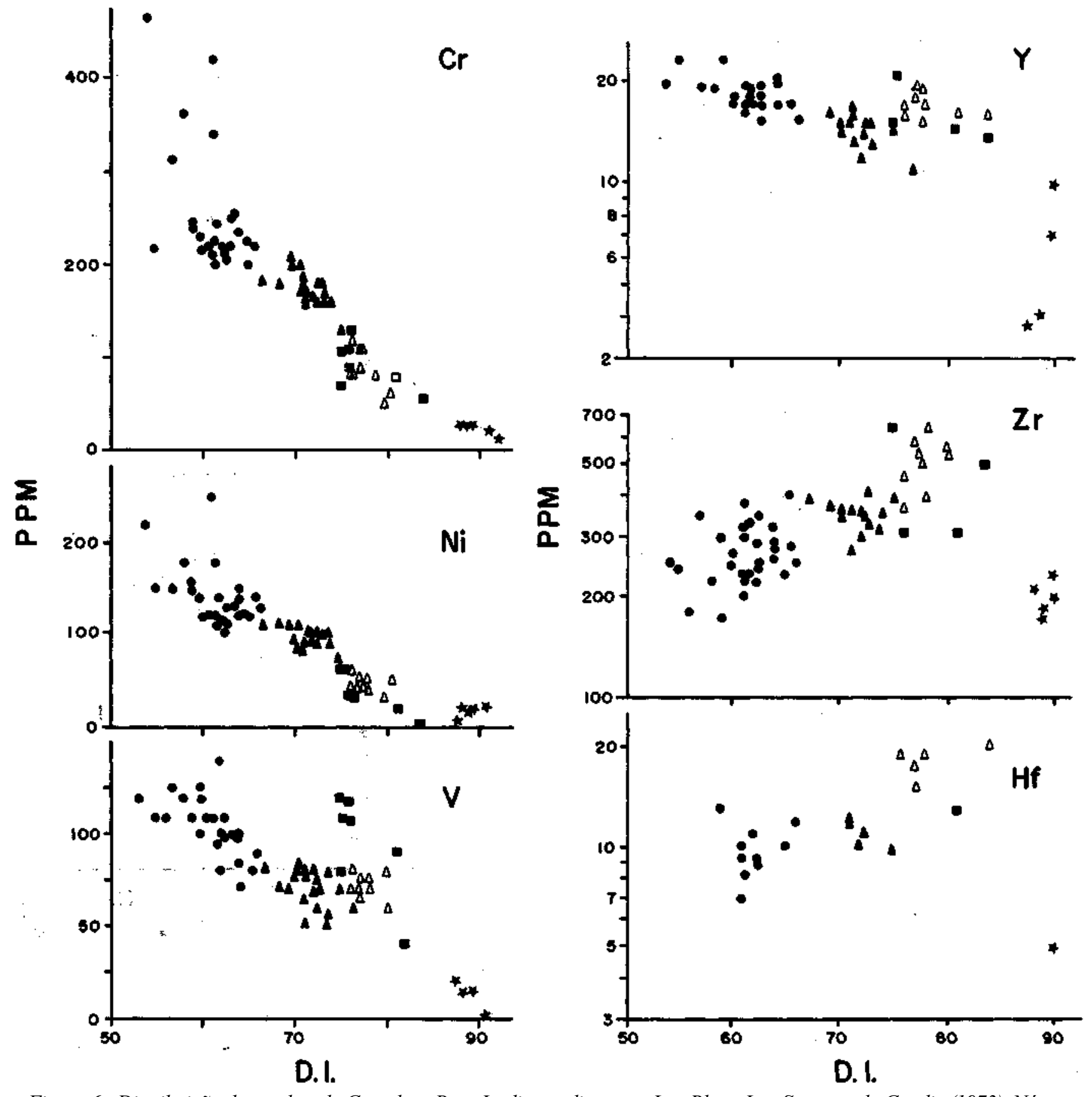

Figura 6 - Distribuição das rochas do Complexo Bom Jardim no diagrama Log Rb vs. Log Sr, segundo Condie (1973). Números em $\mathrm{km}$ referem-àe ao espessamento crustal. Símbolos, como na figura 2

Figure 6 - Log Rb - Log Sr diagram showing the distribution of the Bom Jardim granitoids, after Condie (1973). Symbols as in figure 2

evoluídos parece refletir ausência ou escassez de feldspatos na fonte. Se durante a evolução da fácies SMG ocorreu fracionamento de pequena quantidade de feldspatos, anomalias negativas de $\mathrm{Eu}$ foram compensadas por anomalias positivas resultantes do fracionamento de anfibólio. Nas fácies nas quais às evidências apontam origem á partir de cumulus dê feldspato alcalino (SEG), a ausência de anomalias de Eu poderia estar relacionada a condições de alta fugacidade de oxigênio, durante este estágio da diferenciação mâgmática, ò que impediria a entrada de Eu na estrutura dos feldspatos (Drake 1975).

ps padrões de ETR dós granitos (Fig. $1 \mathrm{OB}$ ) são significativamente diferentes dos padrões da suíte sienito-monzonito, com marcantes anomalias positivas de $\mathrm{Eu}\left(\mathrm{Eu}^{*}\right.$ varia de 1,3 a 2,7$)$.

As interpretações e feições características dos trends dos elementos incompatíveis podem ser ilustrados por meio de projeções destes elementos normalizados em relação ao padrão condrito spiderdiagrams. Os fatores de normalização adotados neste trabalho são os sugeridos por Thompson (1982). Todas as fácies da suíte sienito-monzonito mostram spiderdiagrams similares, isto é, depressões significativas em $\mathrm{Nb}$ e Ta, depressões subordinadas de profundidades variadas em Ti, P e U e picos em K, La e Hf(Fig. 12). Os teores de high field strength elements (HFSE) (Nb, Ta, Zr e Hf) são consistentemente mais elevados nas fácies mais evoluídas 

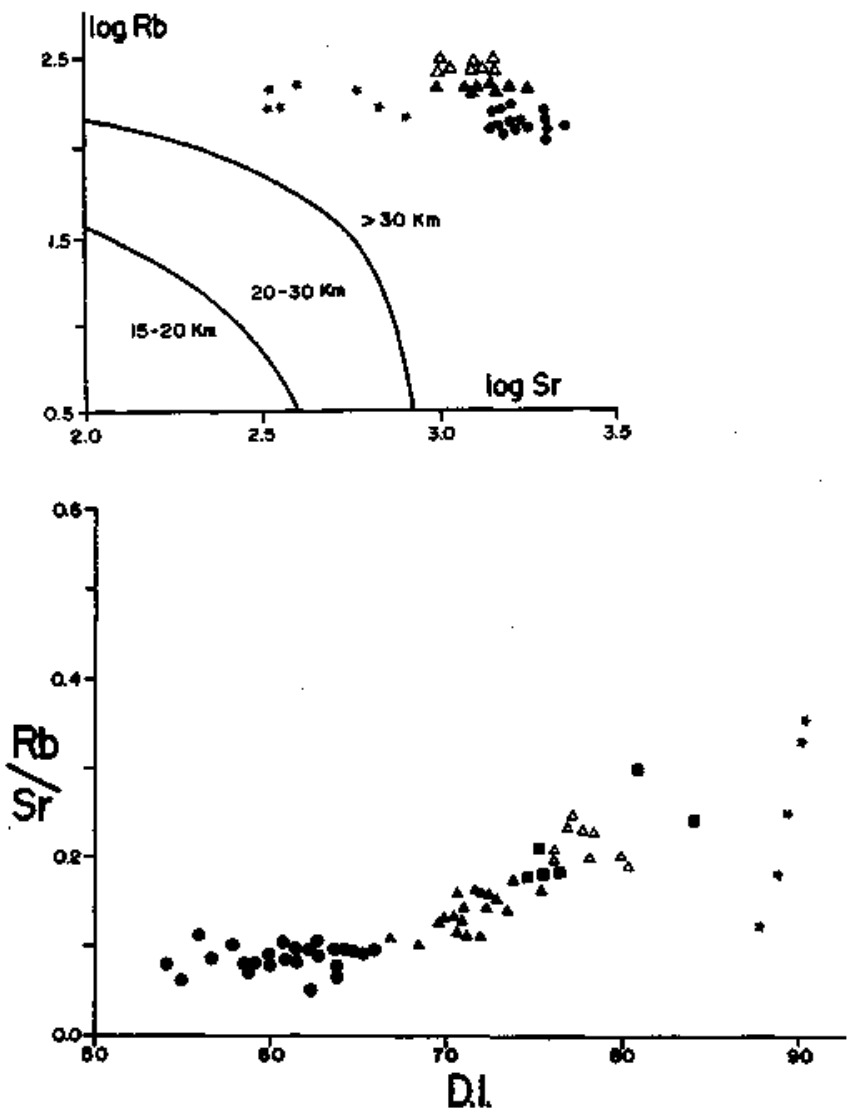

Figura 7 - Rb/Sr vs. D. I. Símbolos como na figura 2 $\mathrm{i}$ igure $7-\mathrm{Rb} / \mathrm{Sr} v$ s. D.I., Symbols as in figure 2

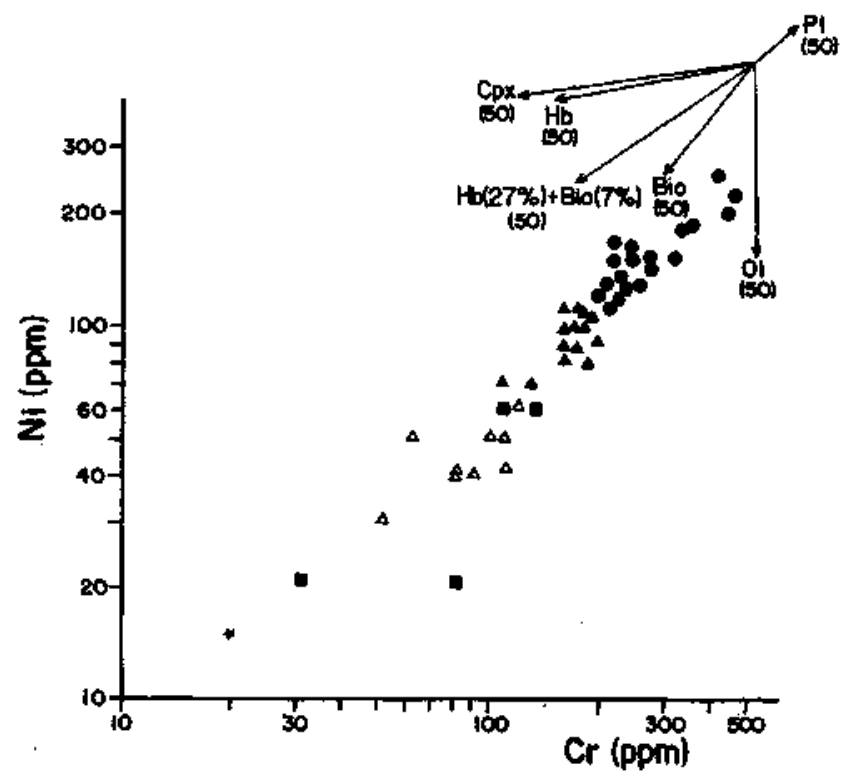

Figura 8 - Projeção logaritmica $\mathrm{Cr}$ (ppm) versus $\mathrm{Ni}$ (ppm) para o Complexo Bom Jardim. Vetores minerais foram calculados usando os'valores de Kd fornecidos por Gill (1978). Símbolos como na figura 2

Figure 8 - Logarithmic, bivariant plot ofNi (ppm) versus $\mathrm{Cr}(\mathrm{ppm})$ for the Bom Jardim complex. Mineral vectors calculated using the Kd values from Gill (1978). Symbols as in figure 2

(LS), indicando incompatibilidade durante a cristalização magmática, excluindo a possibilidade de fracionamento de zircão, titanita e allanita durante a evolução das rochas do

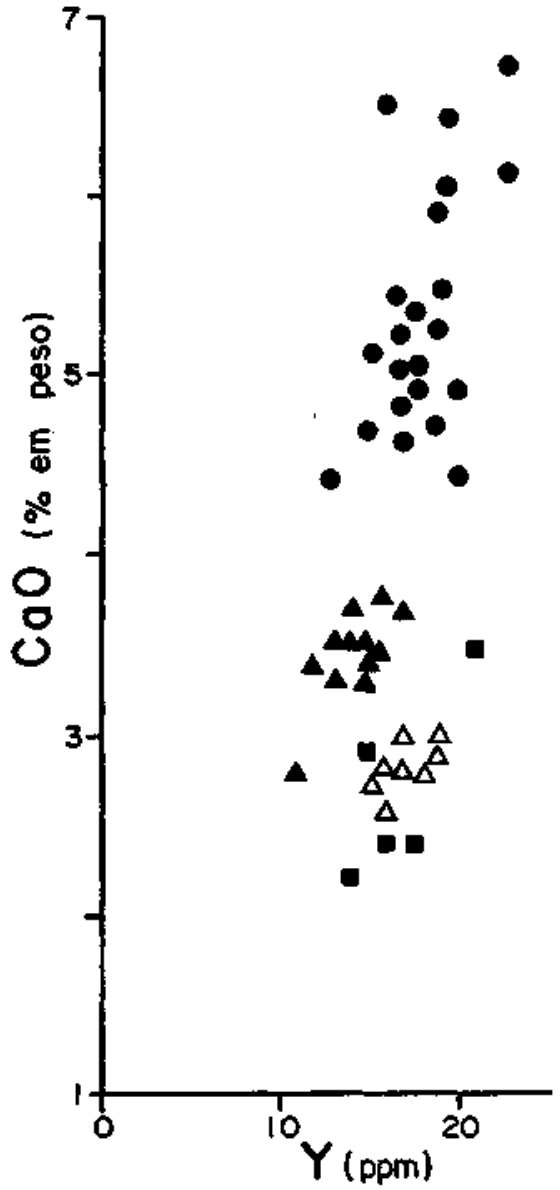

Figura 9 - Projeções dos teores de Y (ppm) versus $\mathrm{CaO}(\%$ em peso) para as rochas do Complexo Bom Jardim. Símbolos como na figura 2

Figure 9 - Variation of $\mathrm{Y}(\mathrm{ppm})$ with $\mathrm{CaO}(\mathrm{wt} \%)$ contents. Symbols as in figure 2

complexo, conforme os coeficientes de partição para Ta, Hf fornecidos por Mahood \& Hildreth (1983) e Worner et al. (1983). Os teores de Rb, Th e K aumentam constantemente das fácies menos evoluídos para as fácies mais evoluídas. As depressões em $\mathrm{P}$ aumentam em profundidade, das fácies menos evoluídos (SEG) para os mais evoluídas (LS), indicando fracionamento da apatita. Análises por microssonda eletrônica em apatita do Complexo Bom Jardim (Guimarães 1989) mostram baixos teores de ETR. Logo, fracionamento moderado de apatita não causaria significantes modificações nos padrões de ETR das rochas do complexo. Pequenas diferenças observadas nos spiderdiagrams das amostras das fácies SMG, em contraste com a maior regularidade observada nas amostras das fácies LS e SM, refletem processos localizados de mistura de magmas e de contaminação com os metassedimentos encaixantes.

Spiderdiagrams com depressões em Nb, Ta, Ti e P são típicos de magmas relacionados a subducção. Estas depressões em $\mathrm{Nb}$ e Ta têm sido explicadas como resultantes da retenção de $\mathrm{Nb}$ e Ta no resíduo, durante a geração de magmas em ambiente hidratado, com fase residual sólida rica em minerais de Ti (Saunders et al. 1980, Foley \& Wheller 1990 e Beccaluva et al. 1991).

CONSIDERAÇÕES PETROGENÉTICAS E CONCLUSÕES A falta de anomalia significante de Eu nos padrões de ETR dos monzonitos e sienitos do Complexo Bom Jardim apontam para uma possível fonte livre ou pobre em feldspatos. Isto exclui a maioria das fontes crustais em 

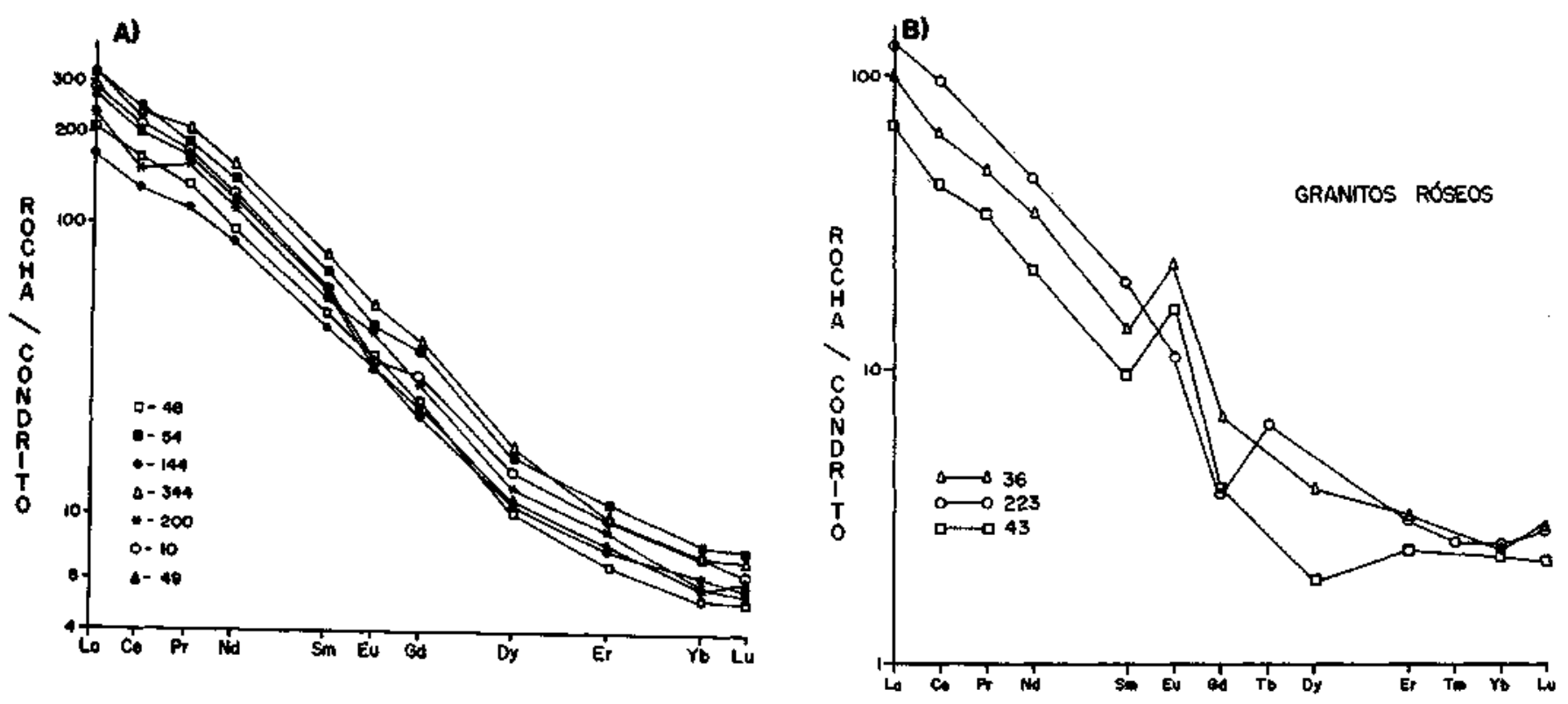

Figura 10 - Projeções dos elementos terras raras normalizados em relação ao condrito, para as diferentes liíologias do Complexo Bom Jardim. A. monzonitos-sienitos e B. granitos. Valores do condrito segundo Nakamura (1974) Figure 10 -Chondrite normalized REE plots forthe different lithologies of the Bom Jardim complex. A. monzonites and syenites and B. granites. Chondrite values are from Nakamura (1974)

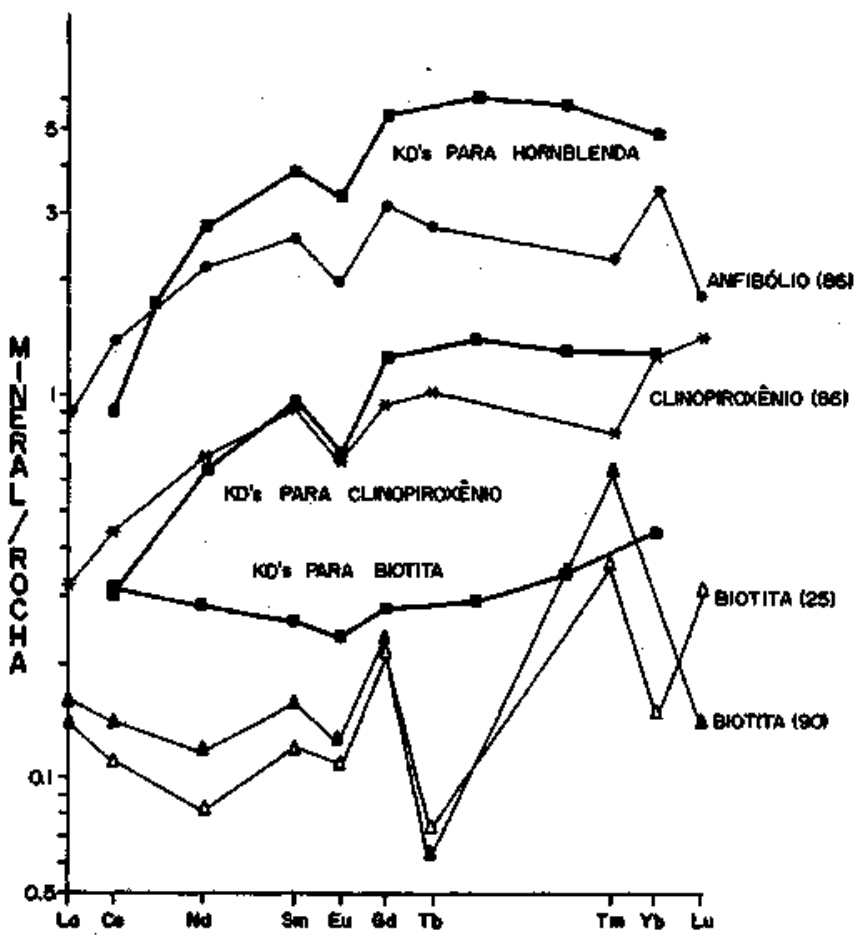

Figura 11- Projeções dos teores de terras raras em anfibólio, clinopiroxênio e biotita normalizados em relação à rocha total. As linhas grossas são baseadas em Kds fornecidos por Hanson (1980)

Figure 11 - Whole rocks normalized REE patterns of amphibole, pyroxene and biotite form the Bom Jardim complex. The thick lines are based on Kds from Hanson (1980)

potencial, isto é: os gnaisses e migmatitos da Faixa PajéuParaíba e do Maciço PE-AL. Os teores elevados dos elementos de transição Ni e Cr, nos membros mais máficos do Complexo Bom Jardim, poderiam sugerir origem a partir da fusão parcial de anfibolito em regiões profundas da crosta continen- tal. Isso implicaria no aparecimento de anomalias negativas de Eu nos membros menos evoluídos. Logo, os elevados teores de $\mathrm{Cr}$ e Ni parecem refletir origem mantélica para as rochas do Complexo Bom Jardim.

Os spiderdiagrams dos membros menos evoluídos do Complexo Bom Jardim são similares a certos magmas primitivos, isotopicamente bem caracterizados de origem mantélica do Caledoniano da Escócia (Fig. 12A). A amostra L8 (Lome Plateau, Thirlwall 1982), a qual representa lava rica em elementos incompatíveis, tem padrão spiderdiagram semelhante àqueles determinados na fácies SMG. Pequenas diferenças ocorrem e se refletem principalmente em teores mais elevados de $\mathrm{Rb}$ nas rochas do Complexo Bom Jardim, indicando maior contaminação crustal, como evidenciado pela razão inicial Sr87/Sr86 $(0,70709)$ mais elevada (Guimarães 1989).

O magma parental dos monzonitos e sienitos do Complexo Bom Jardim poderia ter evoluído de magma básico com baixos teores de elementos incompatíveis, similar em composição ao shoshonito picrítico (amostra MS 143, Thompson et ai 1984, Fig. 12A). Entretanto, a razão La/Yb é baixa $(12,5)$ no shoshonito picrítico, quando comparada às razões determinadas nas rochas do Complexo Bom Jardim (>64). Mas, se a fonte do magma parental das rochas do Complexo Bom Jardim tinhacomposição semelhante a um shoshonito picrítico, o fracionamento da granada, piroxênio e/ou anfibólio teria sido necessário para aumentar a razão $\mathrm{La} / \mathrm{Yb}$ no magma (Noyes et al. 1983). O fracionamento de anfibólio, durante a evolução das rochas do Complexo Bom Jardim, é apoiado pelo grande número de encraves ricos em anfibólio, distribuídos no complexo. Esse modelo é de alguma forma especulativo, desde que rochas de composição shoshonito picrítica, até o presente, não foram descritas na Província Borborema. As comparações com os shoshonitos picríticos e as amostras das lavas do Plateau de Lorne (Escócia) foram utilizadas para demonstrar as analogias químicas entre líquidos derivados do mato e as rochas do Complexo Bom Jardim.

Guimarães et al. (1988) e Guimarães (1989) têm demonstrado que as rochas do Complexo Bom Jardim apresentam todas as características de suíte de rochas relacionadas a processos de subducção, somando-se a isto, as características geoquímicas mantélicas dessas rochas. Um magma com tais 


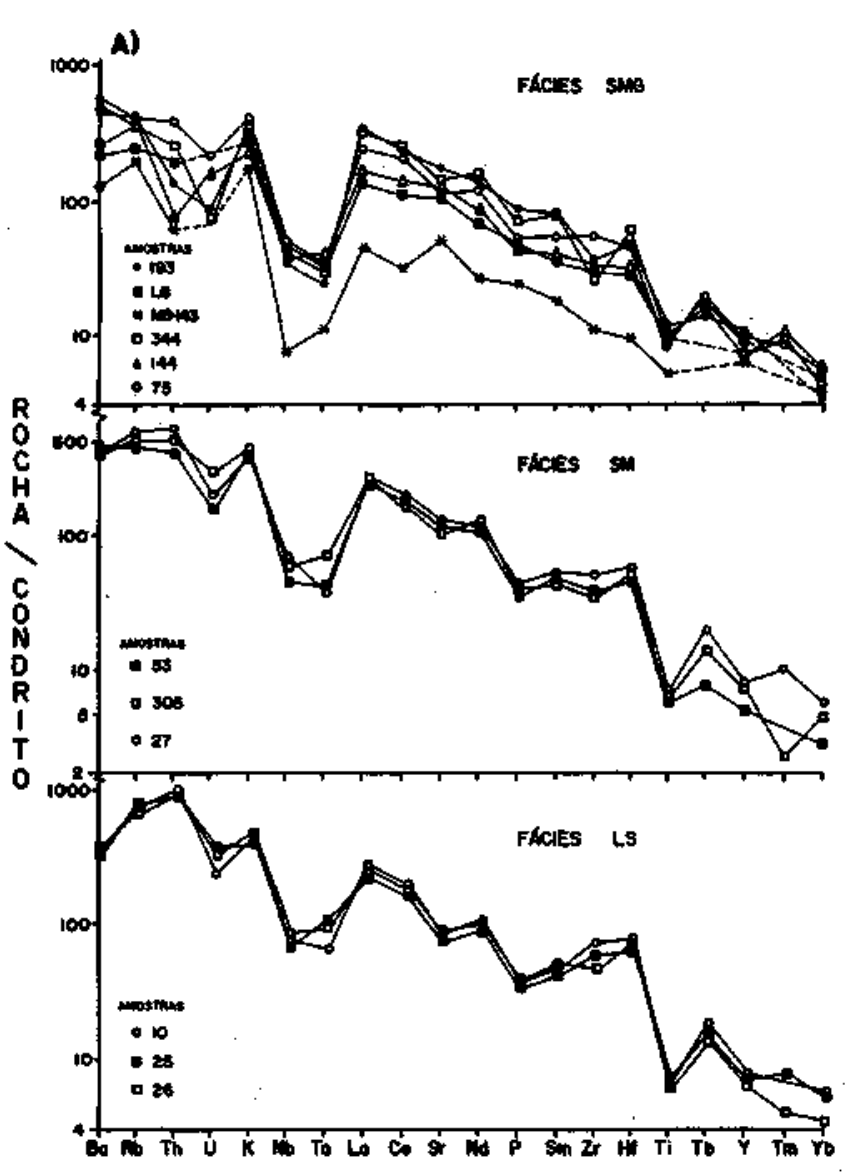

características poderia ser gerado em manto litosférico subcontinental, metassomatizado por fluidos ricos nos elementos incompatíveis $\mathrm{K}, \mathrm{Rb}$ e terras raras leves, possivelmente originados por desidratação de placa oceânica subductada (Maysen 1979). Mistura de diferente tipos de magmas, incluindo magmas gerados por fusão da crosta inferior, podem ocorrer sob a influência desses fluidos (Wyllie 1979, 1983 e Marti 1987). Dados experimentais têm mostrado que peridotito metassomatizado é capaz de gerar magmas cálcio-alcalinos andesíticos a dacíticos (Kushiro 1972, Green 1973, 1976 e Wyllie 1981, 1983), a partir, principalmente, do fracionamento de piroxênio e olivina, com granada e espinélio em menos escala. Tais processos de fracionamento poderiam gerar magmas com geoquímica semelhante aos membros menos evoluídos do Complexo Bom Jardim.

MacKenzie (1989) faz análise da física envolvida na gênese de magmas potássicos durante extensão da litosfera continental e/ou fusão acima de pluma mantélica. Seu modelo mostra que potássio, urânio e tório são acumulados continuamente na porção superior do manto litosférico, logo abaixo da crosta continental, MBL ou no limite mecânico da camada (McKenzie 1989), pela ascensão de pequenas frações de magmas enriquecidos em halogênio e potássio. Tais magmas podem ser gerados por pequena fração de fusão parcial de granadaperidotito. Se voláteis, são concentrados no fundido; pequenas frações de magma (10-3\%) podem ser separadas de uma camada de $100 \mathrm{~km}$ de espessura, se a viscosidade for baixa $(\mathrm{O}, 1$ $\mathrm{Pa} \mathrm{s})$. Apesar do pequeno volume, esses magmas são importantes porque controlam a distribuição do calor no manto e na crosta e, quando resfriam dentro da MBL, anomalias isotópicas podem ser produzidas. Como enfatizado por MacKenzie (1989), estes líquidos não são eutéticos e irão solidificar-se em diferentes profundidades. A refusão desta camada ocorre quando há aquecimento devido a condução de calor por uma pluma ou descompressão por extensão, requerendo perturbações na temperatura da litosfera bem menores do que a

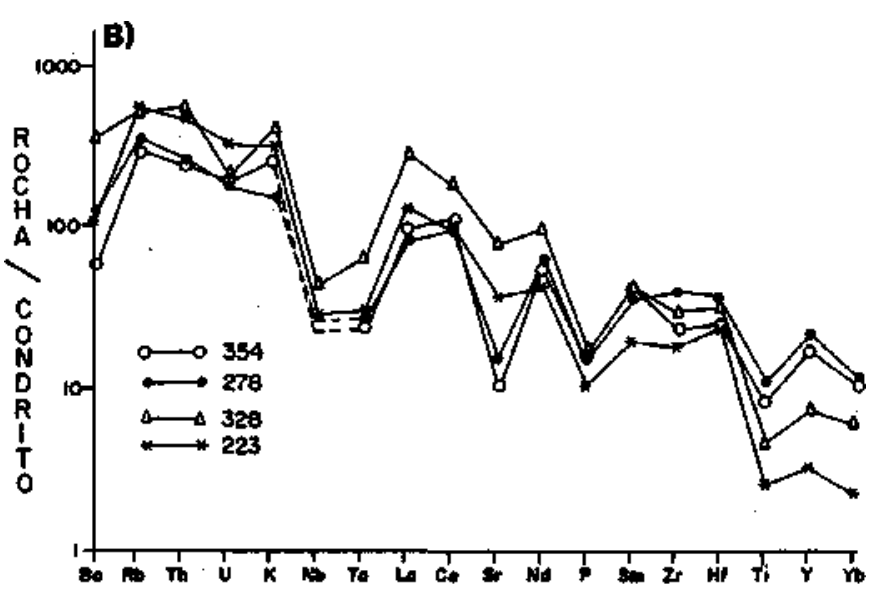

Figura 12 - Padrões dos elementos incompativeis normalizados em relação ao padrão condrito, para as diferentes fades do Complexo Bom Jardim. A. Suite monzonito-sienito e B. granitos (amostras 223 e 328) e metassedimentos encaixantes (amostras 278 e 345) Figure 12 - Chondrite normal ized incompatible elements patterns of the different facies of the Bom Jardim complex. A. monzonite-syenite suite, and B. granites (samples 223 and 328), and metasedimentary country rocks (278 and 354)

necessária para produzir, sob as mesmas condições de pressão, líquidos anidros.

Se a ausência de sutura brasiliana na Província da Borborema vier a se confirmar nos trabalhos geotectonicistas em desenvolvimento, o modelo proposto por McKenzie (1989) será o mais adequando para explicar o magmatismo potássico na Província da Borborema.

O magma parental do complexo teria sido provavelmente acumulado em câmara magmática na crosta inferior onde se deu o fracionamento de anfibólio, biotita e pequenas quantidade de piroxênio, antes do pulso magmático inicial que deu origem à fácies SMG. Este foi seguido por acúmulo de feldspato alcalino, o que desenvolveu a fácies SEG, deixando o magma relativamente enriquecido em anfibólio e biotita dar origem à fácies SM. O estágio final crystal-liquid mush parece ter gerado a fácies LS. As condições redox durante os estágios finais da evolução magmática parecem ter sido oxidantes, aumentando a razão $\mathrm{Eu}^{3+} / \mathrm{Eu}^{2+}$, e não favorecendo o desenvolvimento de anomalia de $\mathrm{Eu}$, que seria normalmente desenvolvida sob condições mais redutoras em rochas de origem cumulática (fácies SEG). Os efeitos de contaminação durante a intrusão parecem menores e localizados.

Muitos autores têm sugerido modelo envolvendo simples fusão crustal para granitos leucocráticos. Entretanto, DePaolo (1981) e Thompson et al. (1984) propuseram modelo genético alternativo envolvendo cristalização fracionada de magma hidratado básico derivado do manto e aprisionado em crosta espessa e quente, onde sofreria progressiva contaminação pelas rochas siálicas encaixantes. A grande similaridade entre os spiderdiagrams dos granitos e os padrões obtidos nos metassedimentos encaixantes (Fig. 12B) parecem indicar que o magma parental destes granitos foi originado a partir de fusão de material crustal.

Segundo Vorma (1976), durante episódio de colisão continental, o calor resultante de cavalgamento de placas 1 itosféricas provoca geração e dispersão de magmas dentro da crosta. Somente quando o regime tectônico compressional é substituído pelo extensional, o magma é capaz de ser coletado para formar câmara magmática. $\mathrm{O}$ fato de os granitos terem sido intrudidós após os monzonitos e sienitos, e de sua intrusão seguir a direção das falhas de rejeito direcional relacionadas ao lineamento Pernambuco, somando-se à assinatura geoquímica de colisão mostrada por esse grupo de rochas 
(Guimarães 1989), sugerem que o modelo proposto por Vorma (1976) parece oferecer a melhor solução para a gênese e intrusão dessas rochas dentro do Complexo Bom Jardim.

\section{Agradecimentos Este trabalho é parte da tese de}

doutoramento do primeiro autor, realizada com apoio financeiro do CNPq (proc. 203242/85). Os autores agradecem ao dr. J. Nolan pelas críticas, ao dr. Terry Williams (Natural Museum, Londres) e a Peter Watkins (Imperial College) pela cooperação na fase de obtenção dos dados.

\section{REFERÊNCIAS BIBLIOGRÁFICAS}

ATHERTON, M.P. \& SANDERSON, L.M. 1985. The chemical variation and evolution ofthe Super-Units ofthe Coastal batholith. In; PITCHER, W.; ATHERTON, M.P.; COBBING, E.J.; BECKINSALE, A.W. eds. Magmatism at a Plate Edge - The Peruvian Andes. Glasgow, Blackie Halsted. p. 208-227.

BATEMAN, P.C. \& DODGE, F.C. W. 1970. Variations ofthe major chemical constituents across the Sierra Nevada batholith. Bull. Geol. Soc. Am., 81:409-420.

BECCALUVA,L.; DIGIROLAMO, P.; SERRI, G. 1991. Petrogenesis an tectonic settinf of the Roman Volcanic Province, Italy. Lithos, 26:191 221.

BERTHE, D.; CHOUKROUNE, P.; JEGOUZO, P. 1979. Orthogneiss, mylonite and non coaxial deformation of granites: the example of South American shear zone. J. Struct. Geol., 1(1 ):31-42.

BEST, M.G. \& MERCI, E.L. 1967. Composition and crystallization of mafic minerals in the Guadalupe igneous complex. Am. Mineral., 52:437-474.

BRITO-NEVES, B.B. 1975. Regionalização Tectônica do Pré-Cambriano Nordestino. São Paulo. (Tese de Doutoramento, IG/USP).

BRITO-NEVES, B.B.; SIAL, A.N.; RAND, H.; MANSO, V. A. V. 1982. The Pernambuco -Alagoas massif. Rev. Bras. Geoc., 12:240-250.

BROWN, G.C.; CASSIDY, J.; LOCKE, C.A.; PLANT, J.; SIMPSON, P.R 1981. Caledonian plutonism in Britain: a summary. J. Geophys. Res. 86:10.502-10.514

CHAPPELL, B.W. \& WHITE, A.J.R. 1974. Two contrasting granite types. Pacific Geology, 8:173-174.

CONDIE, K.C. 1973. Archean magmatism and crustal thickening. Geol. Soc. Am. Bull., 43:187-201.

DEBON, F. \& LE FORT, P. 1983. A chemical-mineralogical classification of cammon plutonic rocks and association. Trans. R. Soc. Edinburgh: Earth Sci., 73:135-149.

DEPAOLO, D.J. 1981. Aneodymium and strontium study of the Mesozoic calcalkakine granitic batholith ofthe Sierra Nevada and Peninsular Ranges, California../. Geophys. Res., 86:10470-10488.

DRAKE, M.J.I 975. The oxidation state of europium as an indicatorof oxygen fugacity. Geochim. Cosmochim. Acta, 39:55-64.

FOLEY, S.F. \& WHELLER, G.E. 1990. Parallels in the origin ofthe geochemical signatures of island arc volcanics and continental potassic igneous rocks: The role of residual titanates. Chem. Geol., 35:1 -18.

FOWLER, N.B. 1985. A GeochemicalandMineralogicallnvestigation of 'the Mobility of UraniumandOther Lithophile Elements During High-Grade Metamorphism. Inglaterra. 327 p. (Tese de Doutoramento, Imperial College).

GILL, J.B. 1978. Role of trace elements partition coefficients in models of andesites genesis. Geochim. Cosmochim. Acta, 42:709-724

GREEN, D.H. 1973. Experimental melting studies on a model upper-mantle composition at $\mathrm{h}$ igh pressure underwater saturated and water-undersaturated conditions. EarthPlanet. Sci. Lett., 79:37-53.

GREEN, D.H. 1976. Experimental testing of equilibrium partial melting of peridotite underwater-saturated, high pressure conditions. Can. Mineral., $14: 255-268$

GUIMARÃES, I.P. 1989. The PetrologicalEvolution andTectonic Association ofthe Bom Jardim Complex, Pernambuco state, Brazil. Inglaterra. 424 p. (Tesede Doutoramento, Imperial College).

GUIMARÃES, I.P.;THOMPSON, R.N.; SILVA, A.F., P. 1988. Bom Jardim intrusive complex; shoshoniticmagmatismasevidenceofcollision tectonics during Upper Proterozoic, N.E. Brazil. In: INTER. CONFERENCE "GEOCHEMICAL EVOLUTION OF THE CONTINENTAL CRUST". Poços de Cal das, 1988. Abstracts... Poços de Caldas, p. 264-270.

HANSON, G.N. 1978. The application oftrace elements to the petrogenesis of igneous rocks of granitic composition. Earth Planet. Sci. Lett., 38:26-46.

HART, S.R. \& ALLEGRE, C.J. 1980. Trace elements constraints on magma genesis. In; HARGRAVES, R.B. ed. Physics ofMagmatic Processes. Nova York, Princeton University Press, p. 121-159.

HUTTON,D.H.W. 1987.Granite emplacementmechanismandtectoniccontrols. Inferences from deformation studies. Trans. R. Soc. Edinburgh, 79(23):245-256

JARDIM DE SÁ, E.F. 1984. Aevoluçâo proterozóica da província daBorborema. In: SIMP. GEOL. NORDESTE, 11. Natal, 1984./1«a/1...Natal,SBG.p. 297-316.

KUSHIRO, 1.1972. Effects of water on the composition of magmas formed at high pressure./ Petrol., 13:311-314.

LAMBERT, R.S.T. \& HOLLAND, J.G. 1974. Yttrium geochemistry applied to petrogenesis utilizing coalcium-yttrium relationships in mineral and rocks Geochim Cosmochim. Acta, 38:1393-1414.

LEAKE, B.E. 1978. Nomenclature of amphiboles. Can. Mineral., 16:501-520.

MAHOOD, G \& HILDRETH, W. 1983. Large partition coefficients for trace elements in high silicarhyolites. Geochem. Cosmochim. Acta, 47:11 -30.

MARTIN, H. 1987. Archean and modern granitoids as indicatorsof changes in geodynamic processes. In: ISGAM. Salvador, 1987. Extended Abstracts. . Salvador, p. 23-24.

MAYSEN, B.0.1979. Trace elements partitioning between garnet peridotite minerals and water-rich vapor: experimental data from 5 to $30 \mathrm{kbar}$. $\mathrm{Am}$. Mineral., 65:274-287.

MCKENZIE,D. 1989. Some remarks on the movement of small melt fractions in the mantle. Earth Planet. Sci. Lett., 95:53-72.

MELLO, A.A.; COSTA, A.C.; MENDES, V.A.; HAMA, M. 1977. Elementos tectono-estruturais do nordeste meridional. Parte dos Estados de Paraíba e Pernambuco. In: SIMP. GEOL. NORDESTE, 8. Campina Grande, 1977. Anais... Campina Grande, SBG. p. 346-367.

NAKAMURA, N. 1974. Determination of REE, Ba, Fe, Mg, $\mathrm{Na}$ and $\mathrm{K}$ in carbonaceous andordinary chondrites. Geochim. Cosmochim. Acta, 38:757775.

NOYES, H.J.; FREY, F.A.; WONES, D.R. 1983. A tale of two plutons: geochemical evidence bearing on the origin and differentiation ofthe Red Lake and Eagle Peak plutons, central SierraNevada, California. J. Geol., 91:487-509.

OLADE.M.A. 1976. Geochemical evolution of copper-bearing granitic rocks of Guichon Creek batholith, British Columbia, Canada. Can. J. EarthSci., 13:199-209.

PARSONS, I. 1978. Feldspar and fluids in cooling plutons. Mineral. Mag., 42:1-27'.

SAUNDERS, A.D.; TARNEY, J.; WEAVER, S.D. 1980. Transverse geochemical variations across the Antartic peninsula; implication forthe genesisofcalc-alkalicmagmas.£a;7/j/V<3«e/. Sci. Lett., 46:344-360.

SHAND, S.J. 1951. Eruptive rocks their genesis, composition, classification, and their relation to ore deposits. New York, Hafner Publishing Company. $488 \mathrm{p}$.

SMITH, J.V. 1974. Feldspar Minerals, v.2. Berlin, Spring Verlag. 690 p.

STRECKEISEN, A. 1976. To each plutonic rock its proper name. Earth Sci. /?ev., 12:1-33.

SYLVESTER, A.G.; MILLER, C.F.; NELSON, A. 1978. Monzonites ofthe White-Inyo Range, Californiaand their relation to the calc-alkaline Sierra Nevada batholith. Bull. Geol. Soc. Am., 89:1677-1687.

TARNEY, J. \& SAUNDERS, A.D. 1979. Trace element constraints on the origin of cordilleran batholith. In: ATHERTON, M.P. \& TARNEY, J. eds. Origin of Granite Batholith. Cheshire, Shivapublishing ltd. p. 90-105.

TAYLOR, S.R. \& MACLENNAN, S.M. 1985. The Continental Crust; its Composition and Evolution. Oxford, Blackwell. 312 p.

THIRL WALL, W.F. 1982. Nd-Sr isotopes across a Caledonian calc-alcaline volcanic arc: implications for source materials. Earth Planet. Sci. Lett., 58:27-50.

THOMPSON, R.N. 1982. Magmatism of the British Tertiary volcanic province. Scott. J. Geol., 18:49-107.

THOMPSON, R.N.; MORRISON, M.A.; HENDRY, G.L.; PARRY, S.L. 1984. An assessment ofthe relative roles of crust and mantle in magma genesis: an elemental approach. In: MOORBATH, S. THOMPSON, R.N.; OXBURGH, E.R. eds. The Relative Contributions of Mantle, Oceanic Crustand Continental Crust to Magma Genesis. London, Trans. r. Soc. London, A310:549-589.

THORTON, C.P. \& TUTTLE, O.F. 1969. Chemistry of igneous rocks. I. Differentiation Index. Am. J. Sci., 258:664-684.

VORMA, A. 1976. On the petrochemistry of rapakivi granites with special reference to the Laitilamassif, southwestern Finland. Geol. Survey Finland, 285:98 p.

WORMER, G.; BENSEN, J.M.; DUCHATEAU, N.; GIJBELS, R SCHIMINCKE.H.V. 1983. Trace element abundances and mineral $/ \mathrm{melt}$ distribution coefficients in phonolites from the Laacher See volcano (Germany). Contr. Mineral. Petrol., 84:152-173.

WYLLIE, P.J. 1979. Magmas and volatile componentes. Am. Mineral., 64:469-500.

WYLLIE, P.J. 1981. Experimental petrology of subduction andesites and batholiths. Trans. Geol. S. Africa, 84:281 -291.

WYLLIE, P.J. 1983. Experimental and termal constraints on the deepseated parentage of some granitoidmagmas in subduction zones. In: ATHERTON, M.P. \& GRIBBLE, C.D. eds. Migmatites Melting and Metamorphism. Orpington, Shiva, p. 12-26.
MANUSCRITO A682 Recebido em 13 de novembro de 1990 Revisão do autor em 10 de março de 1992 Revisão aceita em 24 de março de 1992 